\title{
Toxoplasma gondii infection in meat animals from Africa: Systematic review and meta-analysis of sero-epidemiological studies
}

Aretas Babatoundé Nounnagnon Tonouhewa ${ }^{1}$, Yao Akpo ${ }^{2}$, Philippe Sessou ${ }^{1}$, Camus Adoligbe ${ }^{1}$, Eric Yessinou ${ }^{1}$, Yaovi Gildas Hounmanou ${ }^{1,3}$, Marc Napoléon Assogba ${ }^{1}$, Issaka Youssao ${ }^{1}$ and Souaïbou Farougou ${ }^{1}$

1. Laboratory of Research in Applied Biology, Polytechnic School of Abomey-Calavi, University of Abomey-Calavi, 01 P.O. Box 2009, Cotonou, Benin; 2. Laboratory of Ecology, Health and animal Production, Faculty of Agronomy, University of Parakou, P.O. Box 123 Parakou, Benin; 3. Department of Veterinary Medicine and Public Health, Sokoine University of Agriculture, P.O. Box 3121, Chuo Kikoo, Morogoro, Tanzania.

Corresponding author: Aretas Babatoundé Nounnagnon Tonouhewa,e-mail: tonouhewaaretas@gmail.com, Co-authors: YA: yao.akpo@gmail.com,PS: sessouphilippe@yahoo.fr, CA: adolcam83@yahoo.fr, EY: eric.yessinou@uac.bj, YGH: gilmahu@yahoo.fr, MNA: assonapo1@yahoo.fr, IY: iyoussao@yahoo.fr, SF: farougou@gmail.com

Received: 08-09-2016, Accepted: 10-01-2017, Published online: 16-02-2017

doi: 10.14202/vetworld.2017.194-208 How to cite this article: Tonouhewa ABN, Akpo Y, Sessou P, Adoligbe C, Yessinou E, Hounmanou YG, Assogba MN, Youssao I, Farougou S (2017) Toxoplasma gondii infection in meat animals from Africa: Systematic review and meta-analysis of sero-epidemiological studies, Veterinary World, 10(2): 194-208.

\begin{abstract}
Aim: Toxoplasma gondii is an ubiquitous apicomplexan parasite which causes toxoplasmosis in humans and animals. Felids especially cats are definitive hosts and almost all warm-blooded mammals, including livestock and human can serve as intermediate hosts. Food animals can be reservoirs for $T$. gondii and act as one of the sources for parasite transmission to humans. The objective of this study is to collect serological data on the prevalence of anti-T. gondii antibody, and risk factors for certain food animals from Africa to provide a quantitative estimate of $T$. gondii infection among these species from different African countries.
\end{abstract}

Materials and Methods: Four databases were used to search seroepidemiological data on the prevalence of anti-T. gondii antibody in food animals between 1969 and 2016 from African countries. The search focused on data obtained by serologic test in food animals and meta-analyses were performed per species.

Results: A total of 30,742 individual samples from 24 countries, described in 68 articles were studied. The overall estimated prevalence for toxoplasmosis in chicken, camel, cattle, sheep, goat, pig were 37.4\% (29.2-46.0\%), 36\% (18-56\%), 12\% (8-17\%), 26.1\% (17.0-37.0\%), 22.9\% (12.3-36.0\%), and 26.0\% (20-32.0\%), respectively. Moreover, major risk factor of infection was age, farming system, and farm location.

Conclusions: A significant variation in the seroepidemiological data was observed within each species and country. The results can aid in an updated epidemiological analysis but also can be used as an important input in quantitative microbial risk assessment models. Further studies are required for a better and continual evaluation of the occurrence of this zoonotic infection.

Keywords: animal health, meta-analysis, Toxoplasmosis, zoonosis.

\section{Introduction}

Toxoplasma gondii is a coccidian parasite that is globally widespread and causes a common infection in animal and human. The parasite was described for the first time in a North African rodent (Ctenodactylus gondii) independently by Nicolle, Manceaux, and Splendore in 1908 [1]. Felids especially cats are definitive hosts and represent the key element in the epidemiology of disease caused by this parasite. Almost all warmblooded mammals, including livestock, and human can serve as intermediate hosts [2]. T. gondii can infect all homeotherms and is responsible for many abortions and fetal malformations in human and animal [3].

Copyright: Tonouhewa, et al. Open Access. This article is distributed under the terms of the Creative Commons Attribution 4.0 International License (http://creativecommons.org/licenses/ by/4.0/), which permits unrestricted use, distribution, and reproduction in any medium, provided you give appropriate credit to the original author(s) and the source, provide a link to the Creative Commons license, and indicate if changes were made. The Creative Commons Public Domain Dedication waiver (http:// creativecommons.org/publicdomain/zero/1.0/) applies to the data made available in this article, unless otherwise stated.
According to estimates, approximately $1 / 3$ of the world's population would be infected [4] and T. gondii infection represent the most prevalent parasitic zoonotic disease worldwide [5]. This parasite is present on all continents, and the rate of infection vary highly according to areas [2]. However, climate change has led to an increase of $\mathrm{T}$. gondii infections in different regions of the world as a result of changing environmental conditions [6].

Humans get infected after ingesting undercooked or raw meat, by ingesting cat-shed oocysts via contaminated soil, food, water or congenitally by transplacental transmission of tachyzoites [5]. However, the clinical disease is seen only in few cases with serious consequences in immunocompromised people and pregnant women [7]. Toxoplasmosis is a major cause of reproductive failure in sheep, goats, and pigs $[8,9]$ and also recognized as a serious problem in immunocompromised patients particularly AIDS patient [10,11]. Furthermore, recent studies have shown that toxoplasmosis is a risk factor for 
schizophrenia [12], epilepsy [13], and traffic accidents [14] and highly virulent atypical strains of $T$. gondii have been incriminated with pneumonia, even in immunocompetent people [15].

Toxoplasmosis, especially cerebral toxoplasmosis has become the most common opportunistic infection of the central nervous system during HIV infection in the world [10,11]. Africa is the most continent affected by HIV/AIDS infection that affects about 30 million people on the continent [16]. Unluckily countries most affected are those least able to meet the cost of prevention and treatment of disease. Thus, toxoplasmosis has become an important public health problem on the continent account to the severity of the infection in AIDS patients more frequent in Africa. The absence of public health schemes to manage the spread of this disease places African populations at risk of ongoing and possibly increasing incidence and prevalence, as well as a corresponding increase in mortality and morbidity due to toxoplasmosis [17].

Food animals are important livestock species, especially in developing countries and their products (meat and milk) are used in various parts of the world. Pork and chicken are the most consumed meat in the world with global production estimated at 115.5 and 108.7 million tons in 2014 [18]. In Africa; cattle, chicken, sheep, goat, pig, and camel represent the most consumed animal species. According to estimate, the meat production on the continent was estimated at 17352 thousands of tons in 2013 and increasing every year [18]. Food animals can be reservoirs for T. gondii and act as one of the sources for parasite transmission to humans. Many epidemiologic studies have found an association between consumption of undercooked or raw meat and T. gondii infection in human $[19,20]$. Based on limited population-based data, the Food and Agriculture Organization and World Health Organization estimated that approximately $22 \%$ of human $T$. gondii infections are meatborne [21].

To detect $T$. gondii in meat animal, three methods have been used. These methods include serological assays, bioassay, and polymerase chain reaction (PCR) [22]. Among these three methods, serological assays are rapid and have good accuracy for detecting anti-T. gondii antibodies in food animals [23-25] and the modified agglutination test (MAT) and enzymelinked immunosorbent assay (ELISA), are the most commonly used serological test.

Compared to other continents, few studies have been conducted on toxoplasmosis in Africa. Studies available on the seroprevalence of toxoplasmosis in African countries are still fragmented, except some countries including Ethiopia where the infection is well documented. Therefore, there have been a few studies on seroprevalence rates of $T$. gondii in animal species on the continent, and the results of the available studies are sometimes contradictory.

Meta-analysis is a method to synthesize the results of various studies for a given question and was applied to a wide range of food safety questions [26]. The quantitative results obtained from meta-analysis were used as inputs in risk assessment models [27]. According to Gliner al. [28], the advantages of performing a meta-analysis include providing summary statistics based on multiple individual studies, increasing precision in estimating effects, and taking the size of studies into account.

The aim of this systematic review and meta-analysis study is to collect serological data on the prevalence of anti- $T$. gondii antibody, and risk factors for most consumed food animals from Africa to provide a quantitative estimate of $T$. gondii infection among these species.

\section{Materials and Methods}

\section{Ethical approval}

This study did not require an ethical approval as it was based on information/data retrieved from published studies already available in the public domain.

\section{Data sources and searches}

We conducted a systematic literature review on the seroprevalence of $T$. gondii among food animals in African countries as per preferred reporting items for systematic reviews and meta-analyses criteria [29]. Relevant studies were identified by searching four literature databases including PubMed, Web of Science, Scopus, and Google Scholar. No time limitation was imposed. The search criteria were specified in advance and the search was executed on 11/12/2015 and last updated on $01 / 04 / 2016$. The search string used was the following: "toxoplasma" OR "toxoplasmosis" AND "seroprevalence" OR "seroepidemiology" AND "sheep" OR "goat" OR "pig" OR "cattle" OR "chicken" OR "camel" AND "Africa".

\section{Data collection and eligibility criteria}

For this review, only articles written in English and French were considered. Two investigators studied titles and abstract of all the articles and retrieved data. Several criteria were used to select eligible studies (1) study were performed in animals raised in different African countries; (2) the prevalence of $T$. gondii had to be detected by serologic methods (ELISA, MAT, direct agglutination test [DAT], modified direct agglutination test [MDAT], indirect fluorescent antibody test [IFAT], latex agglutination test [LAT], and Sabin and Feldman test [SFT]); (3) samples had to originate from food animals (cattle, chicken, camel, pigs, sheep and goat); (4) samples had to be collected from animals which were naturally infected; (5) sampling strategy had to be directed toward a random population; (6) the sample size was $<35$. The extracted data included: Year of publication, host, country of the study, sample size, number of cases, diagnostic test, and risk factors. Reference lists of full-text publications and textbooks were also examined to identify studies not retrieved by the original search. All studies were coded according to the previously chosen parameters, and data were recorded in Microsoft Excel table. 


\section{Quality and bias assessment of eligible studies}

Each eligible study was assessed for quality and bias using the risk of bias tool, which is a methodological quality assessment checklist for prevalence studies [30]. 10 questions were contained in this checklist, and each of the 10 questions was scored 1 or 0 based on the quality of each eligible study [30]. This questions were as follows:

Q1: Was the study's target population a close representation of the national population in relation to relevant variables?

Q2: Was the sampling frame a true or close representation of the target population?

Q3: Was some form of random selection used to select the samples, or, was a census undertaken?

Q4: Was the likelihood of non-response bias minimal?

Q5: Were data collected directly from the subjects (as opposed to a proxy)?

Q6: Was an acceptable case definition used in the study?

Q7: Was the study instrument that measured the parameter of interest shown to have reliability and validity (if necessary)?

Yes (if using MAT, ELISA, DAT, and MDAT),

No (using other serologic detection methods).

Q8: Was the same mode of data collection used for all subjects?

Q9: Was the length of the shortest prevalence period for the parameter of interest appropriate? Q10: Were the numerator(s) and denominator(s) for the parameter of interest appropriate?

Eight different detection methods were used in these eligible studies. For question 7, which was to determine the reliability and validity of the measurement, MAT, ELISA, DAT and MDAT were considered as reliable diagnostic methods (score 1) [24,25], and other diagnostic tests such as LAT, indirect immunoflourescent assay (IFA), indirect hemagglutination assay (IHA), SFT, were determined as unreliable methods (score 0). A quality score was determined by rescaling the sum of scores of each eligible study between 0 and 1 [30]. Quality assessment was completed independently by two assessors, and a table of quality score computation for each eligible study is provided in the Supplementary Table-S1.

\section{Data analysis}

Data were recorded in Microsoft Excel spreadsheet and analysed by MetaXL version 4.0 software (EpiGear Int Pty Ltd., Wilston) [31] for the meta-analyses and graphed as forest plot. For pooled prevalence analysis, random effects model was adopted over fixed effect model because there is more robust when analyzing heterogeneous studies [32]. Data were transformed by a double arcsine transformation as described by Barendregt et al. [33] to stabilize the variance. Publication bias was assessed by funnel plots representing the double arcsine transformation of the prevalence against the standard error [34]. Heterogeneity among studies was evaluated by
Cochrane $\mathrm{Q}$ and $\mathrm{I}^{2}$ statistical methods. A significant value $(\mathrm{p}<0.05)$ in the Cochrane $\mathrm{Q}$ method suggests a real effect difference in the meta-analysis. A value of $\mathrm{I}^{2}$ was used to measure the inconsistency across studies. Values of $25 \%, 50 \%$, and $75 \%$ were considered as having a low, moderate, and high degree of heterogeneity, respectively [35].

\section{Results}

Schematic flow diagram describing the selection of relevant studies Figure-1.

\section{Characteristics of eligible studies}

Figure-1 shows the flow diagram of the selection of eligible studies. A total of 5700 papers published between 1969 and 2016 were identified by literature search among the four database searched. After duplicate removed and irrelevant studies based on titles and abstracts, 81 articles were retrieved for detailed fulltext analysis. 13 were excluded due to the following reasons: Two were not available; the sample size was lower than 35 in four study; the diagnosis was established on the basis of other methods than serologic test in seven studies. Table- 1 shows the characteristics of included studies [36-103]. Finally, a total of 68 articles from 24 countries were included in this systematic review and meta-analysis study. Approximately, $60 \%(41 / 68)$ of the studies were published within the last 10 decade (2007-2016) of the review period. The regional distribution of studies was west Africa (18), East Africa (17), North Africa (21), Southern Africa (8), and Central Africa (4). Our analysis included a totally 30,742 individual samples distributed as follows: 14,272 sheep, 6355 goats, 3366 cattle, 2798 chickens, 2080 pigs, and 1621 camels. Eight different types of diagnostic tests were employed to evaluate T. gondii infection. These diagnostic methods were MAT, ELISA, IHA, DAT, MDAT, IFA, LAT, and SFT. The most used diagnostic tests in 47 year surveys were ELISA and MAT in 24 and 20 studies, which was followed by LAT (14), IHA (13), DAT (6), IFA (6), MDAT (3) and SFT (1). Sensitivity and specificity of diagnostic test are described in Table- 2 as reported in literature.

\section{Quality and bias assessments}

Supplementary Table-S1 (Appendix) represents the quality score of different eligible study. The quality score in 54/84 eligible studies ranged from 6 and 8 (Table-S1) [36-103]. It shows that the risk of bias in these studies was moderate. Besides, many of the eligible studies were conducted in regional and local farms or slaughterhouses, which were not representative of the national population of animals sampled in these countries. Only 5 of the 84 studies were conducted at the national level (Table-S1). Moreover, studies on animal toxoplasmosis were available only in 24 countries out of 54 of African continent. The risk of bias due to quality deficiency in eligible studies was mainly due to external validity criteria, while the flaws internal validity recorded 


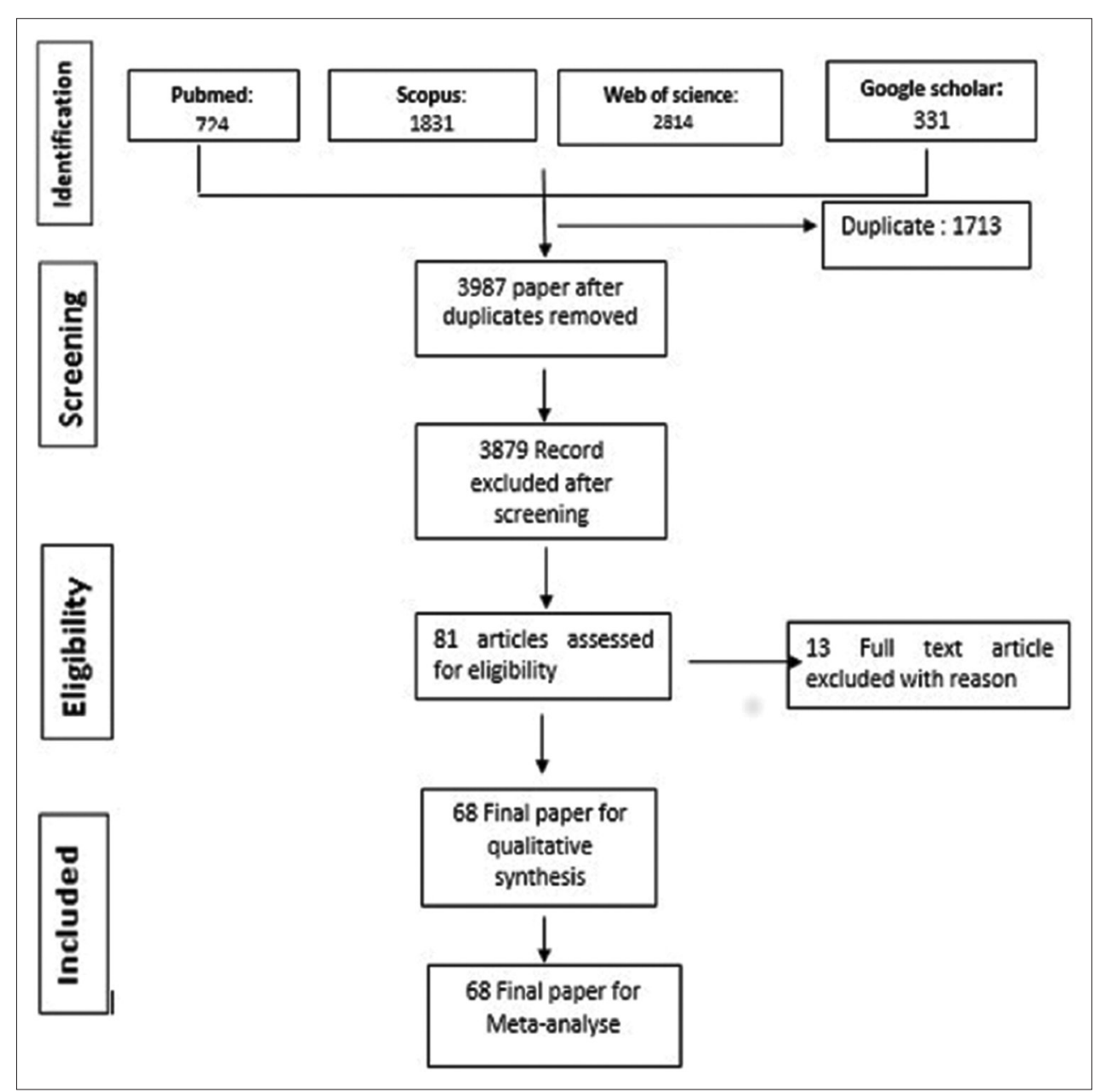

Figure-1: Schematic flow diagram describing the selection of relevant studies.

in eligible studies concerned the use of diagnostic tests other than reference methods such as ELISA and MAT (Table-2) [104]. Finally, the symmetry in the funnel plots ruled out substantial publication bias (Figure-2).

\section{Population prevalence in food animals}

Prevalence of anti-T. gondii antibody in sheep

Data from 27 studies from 17 countries were obtained among sheep. 10 studies used ELISA, 6 studies used MAT, 5 used LAT, 2 used IHA and IFA, DAT and MDAT were used in 1 study, respectively. A total number of individual samples was 14,272. The prevalence of toxoplasmosis in sheep varied from $4.30 \%$ to $68.00 \%$. The random effect model used in the meta-analysis (Figure-3) gave an overall estimated prevalence of $26.1 \%$ (95\% confidence interval [CI] $17.0-37.0 \%$ ). The result of heterogeneity was also $96.83 \%$ (95\% CI $96.18-97.38 \%$ ) for the degree of inconsistency.

\section{Prevalence of anti-T. gondii antibody in goats}

The data obtained from $T$. gondii infection in goat result from 17 studies from 9 countries. The reported prevalence ranged from $3.6 \%$ to $74.8 \%$. For diagnostic methods, 5 studies performing ELISA, 2 studies performing LAT, 2 studies, performing MDAT, IFAT, IHA, respectively, and 1 study performing MAT and DAT, respectively. The total number of individual samples was 6355 . The random effect model (Figure-4) gave an overall estimated prevalence of $22.9 \%$ (95\% CI $12.3-36.0 \%)$. The result of heterogeneity was also $99.1 \%$ (95\% CI $99.0-99.3 \%)$ for the degree of inconsistency.

\section{Prevalence of anti-T. gondii antibody in cattle}

Information on $T$. gondii infection in cattle was obtained from 11 studies from 8 countries. 5 studies performing LAT; 4 studies performing ELISA; 4 studies performing IFAT and IHA, respectively. The total number of individual samples was 3366. T. gondii infection prevalence among cattle ranged from 3.6\% to $32 \%$. The random effect model (Figure-5) gave an overall estimated prevalence of $12 \%(95 \% \mathrm{CI}$ $8-17 \%, \mathrm{p}<0.001)$. The result of heterogeneity was also 92.56\% (95\% CI 88.65-95.12) for the degree of inconsistency. A detailed description of each study is given in Figure-5.

\section{Prevalence of anti-T. gondii antibody in camels}

For camels, 6 studies from 4 African countries were obtained. Most countries concerned were East African countries: Sudan, Ethiopia, and Somalia. 
Table-1: Characteristics of included studies.

\begin{tabular}{|c|c|c|c|c|c|c|c|c|}
\hline Study No & Country & Author & Year & Hosts & Method & $\begin{array}{l}\text { Sample } \\
\text { size }\end{array}$ & $\begin{array}{l}\text { Positive } \\
\text { (\%) }\end{array}$ & $\begin{array}{l}\text { Quality } \\
\text { score }\end{array}$ \\
\hline 1 & Burkina-Faso & Bamba et al. [36] & 2016 & Pig & MAT & 300 & $87(29)$ & 8 \\
\hline 2 & Ethiopia & Gebremedhin et al. [37] & 2015 & Chicken & MAT & 601 & $183(30.50)$ & 9 \\
\hline 3 & Egypt & Abdel-Hafeez et al. [38] & 2015 & Goat & IHAT & 100 & $64(64)$ & 7 \\
\hline 4 & Algeria & Dechicha et al. [39] & 2015 & $\begin{array}{l}\text { Sheep, Goat, } \\
\text { Cattle }\end{array}$ & IFAT & 714 & $59(8.26)$ & 6 \\
\hline 5 & Nigeria & Onyiche et al. [40] & 2015 & Cattle, Pig & ELISA & 512 & $117(22.85)$ & 9 \\
\hline 6 & Sudan & Elfahal et al. [41] & 2015 & Cattle & ELISA & 181 & $24(13.30)$ & 6 \\
\hline 7 & Ethiopia & Gebremedhin et al. [42] & 2015 & Pig & DAT & 402 & $129(32.10)$ & 9 \\
\hline 8 & Ethiopia & Hadush et al. [43] & 2015 & Camel & DAT & 384 & $262(68.20)$ & 9 \\
\hline 9 & Tunisia & Lahmar et al. [44] & 2015 & $\begin{array}{l}\text { Sheep, Goat, } \\
\text { Cattle }\end{array}$ & MAT & 261 & $82(36.78)$ & 7 \\
\hline 10 & South-Africa & $\begin{array}{l}\text { Hammond-Aryee } \\
\text { et al. [45] }\end{array}$ & 2015 & Sheep & ELISA & 292 & $23(8.00)$ & 9 \\
\hline 11 & Tunisia & Boughattas et al. [46] & 2014 & Chicken & MAT & 40 & $40(100)$ & 8 \\
\hline 12 & Nigeria & Ayinmode et al. [47] & 2014 & Chicken & MAT & 225 & $81(40.40)$ & 9 \\
\hline 13 & Senegal & Davoust et al. [48] & 2014 & $\begin{array}{l}\text { Cattle, Goat, } \\
\text { Horse, Sheep }\end{array}$ & MAT & 419 & $148(35.33)$ & 8 \\
\hline 14 & Ethiopia & $\begin{array}{l}\text { Gebremedhin and } \\
\text { Gizaw [49] }\end{array}$ & 2014 & Sheep, Goat & ELISA & 184 & $48(26.08)$ & 9 \\
\hline 15 & Ethiopia & Gebremedhin et al. [50] & 2014 & Sheep, Goat & DAT & 628 & $50(17.62)$ & 9 \\
\hline 16 & Sudan & Medani and Kamil [51] & 2014 & Cattle, Sheep & ELISA & 540 & $153(28.33)$ & 7 \\
\hline 17 & Somalia & Kadle $[52]$ & 2014 & Camel & LAT & 64 & $4(6.3)$ & 7 \\
\hline 18 & Ethiopia & Gebremedhin et al. [53] & 2014 & Camel & DAT & 455 & $220(49.62)$ & 9 \\
\hline 19 & Ethiopia & Tilahun et al. [54] & 2013 & Chicken & MAT & 64 & $41(64.00)$ & 9 \\
\hline 20 & Egypt & Aboelhadid et al. [55] & 2013 & Chicken & MAT & 215 & $30(13.95)$ & 8 \\
\hline 21 & Ethiopia & Zwedu et al. [56] & 2013 & Goat & ELISA & 927 & $183(19.70)$ & 9 \\
\hline 22 & Tanzania & Swai and Kaaya [57] & 2013 & Goat & LAT & 337 & $65(19.30)$ & 8 \\
\hline 23 & South-Africa & Ndou et al. [58] & 2013 & Cattle & ELISA & 178 & $37(20.8)$ & 8 \\
\hline 24 & Nigeria & $\begin{array}{l}\text { Ayinmode and } \\
\text { Olaosebikan [59] }\end{array}$ & 2013 & Pig & ELISA & 100 & $25(25)$ & 8 \\
\hline 25 & Ethiopia & Gebremedhin et al. [60] & 2013 & Sheep & ELISA & 1130 & $357(31.59)$ & 9 \\
\hline 26 & Burkina-Faso & Bamba et al. [61] & 2013 & Sheep & MAT & 339 & $96(28.3)$ & 8 \\
\hline 27 & Libya & Al-Mabruk et al. [62] & 2013 & Sheep & LAT & 5806 & $4120(71.00)$ & 9 \\
\hline 28 & Tunisia & Gharbi et al. [63] & 2013 & Sheep & ELISA & 350 & $38(10.85)$ & 8 \\
\hline 29 & Egypt & Barakat et al. [64] & 2012 & Chicken & ELISA & 125 & $48(38.40)$ & 8 \\
\hline 30 & Madagascar & Rakotoharinome et al. [65] & 2012 & Pig & ELISA & 250 & $57(22.80)$ & 8 \\
\hline 31 & Tanzania & Swai and Schoonman [66] & 2012 & Cattle & LAT & 51 & $06(12.80)$ & 6 \\
\hline 32 & Sudan & Khalil and Abdel Gadir [67] & 2011 & $\begin{array}{l}\text { Cattle, Camel, } \\
\text { Sheep }\end{array}$ & LAT & 200 & $76(38.00)$ & 7 \\
\hline 33 & Tunisia & $\begin{array}{l}\text { Boughattas and } \\
\text { Bouratbine [68] }\end{array}$ & 2011 & Sheep & MAT & 158 & $28(17.70)$ & 9 \\
\hline 34 & Nigeria & Kamani et al. [69] & 2010 & Sheep, Goat & ELISA & 744 & $42(5.45)$ & 8 \\
\hline 35 & Egypt & Ibrahim et al. [70] & 2009 & Cattle & ELISA & 93 & $10(10.75)$ & 5 \\
\hline 36 & Ghana & Dubey et al., [71] & 2008 & Chicken & MAT & 85 & $40(47.00)$ & 7 \\
\hline 37 & Uganda & Lindstrom et al. [72] & 2008 & Chicken & MAT & 50 & $25(50.00)$ & 8 \\
\hline 38 & Egypt & Shapaan et al. [73] & 2008 & Sheep & MAT & 300 & $131(43.70)$ & 7 \\
\hline 39 & Ethiopia & Teshale and Dumaitre [74] & 2007 & Goat & MDAT & 641 & $480(74.80)$ & 9 \\
\hline 40 & South-Africa & Samra et al. [75] & 2007 & Sheep & ELISA & 600 & $26(4.30)$ & 9 \\
\hline 41 & Egypt & Dubey et al. [76] & 2003 & Chicken & MAT & 108 & $51(47.20)$ & 8 \\
\hline 42 & Egypt & Deyab and Hassanein [77] & 2005 & Chicken & MAT & 150 & $28(18.1)$ & 9 \\
\hline 43 & Zimbabwe & Hove et al. [78] & 2005 & Goat & IFAT & 312 & $214(68.58)$ & 9 \\
\hline 44 & Tanzania & Schoonman et al. [79] & 2010 & Cattle & LAT & 665 & $24(3.60)$ & 8 \\
\hline 45 & Zimbabwe & Hove et al. [80] & 2005 & Pig & IFAT & 238 & $47(26.79)$ & 8 \\
\hline 46 & Morocco & Sawadogo et al. [81] & 2005 & Sheep & ELISA & 261 & $72(27.60)$ & 9 \\
\hline 47 & Ethiopia & Negash and Tilahun [82] & 2004 & Sheep, Goat & MDAT & 174 & $79(45.40)$ & 9 \\
\hline 48 & $\begin{array}{l}\text { RDC, Mali, } \\
\text { Burkina-Faso and } \\
\text { Kenya }\end{array}$ & Dubey et al. [83] & 2005 & Chicken & MAT & 80 & $29(36.25)$ & 7 \\
\hline 49 & Nigeria & Joshua and Akinwumi [84] & 2003 & Cattle & LAT & 586 & $99(16.9)$ & 8 \\
\hline 50 & Egypt & El-Massry et al. [85] & 2000 & Chicken & MAT & 150 & $28(18.70)$ & 8 \\
\hline 51 & Ghana & Van der Puije et al. [86] & 2000 & Sheep, Goat & ELISA & 1258 & $384(30.52)$ & 10 \\
\hline 52 & Uganda & Bisson et al. [87] & 2000 & Goat & ELISA & 784 & $240(31.00)$ & 10 \\
\hline 53 & Ghana & Arkoh Mensah et al. [88] & 2000 & Pig & ELISA & 641 & $260(40.60)$ & 10 \\
\hline 54 & Zimbabwe & Hove and Dubey [89] & 1999 & Pig & MAT & 97 & $9(09.30)$ & 7 \\
\hline 55 & Egypt & Hilali et al. [90] & 1998 & Camel & DAT & 166 & $29(17.40)$ & 9 \\
\hline 56 & Egypt & $\begin{array}{l}\text { Hassanain and } \\
\text { Elfadaly [91] }\end{array}$ & 1997 & Chicken & IHAT & 600 & $200(33.33)$ & 7 \\
\hline
\end{tabular}


Table-1: (Continued)

\begin{tabular}{|c|c|c|c|c|c|c|c|}
\hline Study No & Country & Author & Year Hosts & Method & $\begin{array}{l}\text { Sample } \\
\text { size }\end{array}$ & $\begin{array}{l}\text { Positive } \\
\quad(\%)\end{array}$ & $\begin{array}{l}\text { Quality } \\
\text { score }\end{array}$ \\
\hline 57 & $\begin{array}{l}\text { Burkina-Faso, } \\
\text { Ivory-Coast, } \\
\text { Djiboutia, Ethiopia, } \\
\text { Niger, Senegal }\end{array}$ & Deconinck et al. [92] & 1996 Sheep & IHAT & 1042 & $15(23.00)$ & 6 \\
\hline 58 & Cameroon & Achu-Kwi and Ekue [93] & 1994 Sheep & LAT & 211 & $67(31.80)$ & 7 \\
\hline 59 & Egypt & $\begin{array}{l}\text { El-Ghaysh and } \\
\text { Mansour [94] }\end{array}$ & 1994 Sheep & MAT & 102 & $50(49.00)$ & 8 \\
\hline 60 & Nigeria & Amin and Silsmore [95] & 1993 Sheep, Goat & LAT & 465 & $37(7.95)$ & 7 \\
\hline 61 & Senegal & Pangui et al. [96] & 1993 Sheep & IFAT & 190 & $88(46.30)$ & 7 \\
\hline 62 & Sudan & Elamin et al. [97] & 1992 Camel & LAT & 482 & $323(67.00)$ & 7 \\
\hline 63 & Zimbabwe & $\begin{array}{l}\text { Pandley and Van } \\
\text { Knapen [98] }\end{array}$ & 1992 Sheep & ELISA & 216 & $13(06.00)$ & 10 \\
\hline 64 & Niger & Weitzman and Stem [99] & 1991 Sheep & LAT & 70 & $10(14.00)$ & 8 \\
\hline 65 & Ethiopia & Bekele and Kasali [100] & $\begin{array}{l}1989 \text { Sheep, Goat, } \\
\text { Cattle }\end{array}$ & IHAT & 2437 & $349(14.32)$ & 8 \\
\hline 66 & Nigeria & Aganga and Belino [101] & 1984 Chicken & IHAT & 250 & $112(44.80)$ & 7 \\
\hline 67 & Nigeria & Falade $[102]$ & 1978 Goat & LAT & 751 & $23(3.06)$ & 7 \\
\hline 68 & Egypt & Rifaat et al. [103] & 1969 Chicken & DAT & 85 & $17(20.00)$ & 7 \\
\hline
\end{tabular}

MAT: Modified agglutination test, DAT: Direct agglutination test, MDAT: Modified direct agglutination test, ELISA: Enzyme-linked immunosorbent assay, LAT: Latex agglutination test, IFAT: Indirect fluorescent antibody test, IHAT: Indirect hemagglutination test

Table-2: Comparing diagnostic methods.

\begin{tabular}{|c|c|c|c|c|}
\hline Diagnostic test & $\begin{array}{c}\text { Study (\%) } \\
N=68\end{array}$ & Sensitivity (\%) & Specificity (\%) & References \\
\hline MAT, DAT, MDAT & 38.23 & 82.9 & 92.29 & Dubey et al. [23] \\
\hline ELISA & 29.41 & 72.9 & 85.90 & Dubey et al. [23] \\
\hline LAT & 17.64 & 45.9 & 96.90 & Dubey et al. [23] \\
\hline IHA & 07.35 & 29.4 & 98.30 & Dubey et al. [23] \\
\hline IFA & 05.88 & 80.40 & 91.40 & Arthur and Blewett [103] \\
\hline SFT & 01.47 & 54,4 & 90,80 & Dubey et al. [23] \\
\hline
\end{tabular}

MAT: Modified agglutination test, DAT: Direct agglutination test, MDAT: Modified direct agglutination test,

ELISA: Enzyme-linked immunosorbent assay, LAT: Latex agglutination test, IHA: Indirect hemagglutination assay, IFA: Indirect immunoflourescent assay, SFT: Sabin and Feldman test

For diagnostic tests, 3 studies used LAT and 3 used DAT. The total number of individual samples was 1621. Prevalence varied from 6.3 to 68.2. The overall estimated prevalence (Figure-6) for toxoplasmosis in camel by random-effect model was 36\% (95\% CI $18-56 \%)$. The result of heterogeneity was also $98.28 \%$ (95\% CI $97.47-98.81 \%$ ) for the degree of inconsistency.

\section{Prevalence of anti-T. gondii antibody in pig}

Data on $T$. gondii infection in pig were obtained from 8 studies from 6 countries in Africa. 4 studies, performing ELISA, 2 studies, performing MAT and 1 study performing DAT and IFAT respectively. A total number of individual sampled was 2330. Prevalence varied from 9.3 to 40.6. Overall estimated prevalence for anti- $T$. gondii antibody in pig (Figure-7) was $26.0 \%$ (95\% CI 20.0-32.2). The result of heterogeneity was also $91.3 \%$ (95\% CI 85.26-94.8) for the degree of inconsistency. Detailed description of each study is given in Figure-7.

\section{Prevalence of anti-T. gondii antibody in chicken}

Out of the 16 sero-epidemiological studies from 8 countries in the African continent, 12 studies used
MAT, 2 used IHA and 1 study used ELISA and SFT, respectively, for diagnostic of anti-T. gondii antibody in chicken. The total number of individual chicken samples for serological testing was 2948. The prevalence of anti-T. gondii antibody ranged from $6.3 \%$ to $100 \%$. The random effect model gave an overall estimated prevalence (Figure-8) of 37.4\% (95\% CI 29.246.0). The result of heterogeneity was also $95.2 \%$ (95\% CI 93.6-96.6) for the degree of inconsistency.

\section{Risk factor}

About 18 papers out of 68 selected articles for this systematic review reported statistically significant risk factors for the presence of anti-T. gondii antibody in different food animals.

Among sheep and goat, six main risk factors for the presence of anti-T. gondii antibody were identified from different studies. It was: Age (Table-1) [49,56,69,86], management farming system (Table-1) [56,75,78], farm location (Table-1) $[57,60,69,86]$, climatic condition (Table-1) [49,74], sex [48,49], and breed (Table-1) [50,78]. Moreover, three of this main risk factors were also identified in cattle namely: Age (Table-1) [40], management system (Table-1) [79], and sex (Table-1) [40]. 


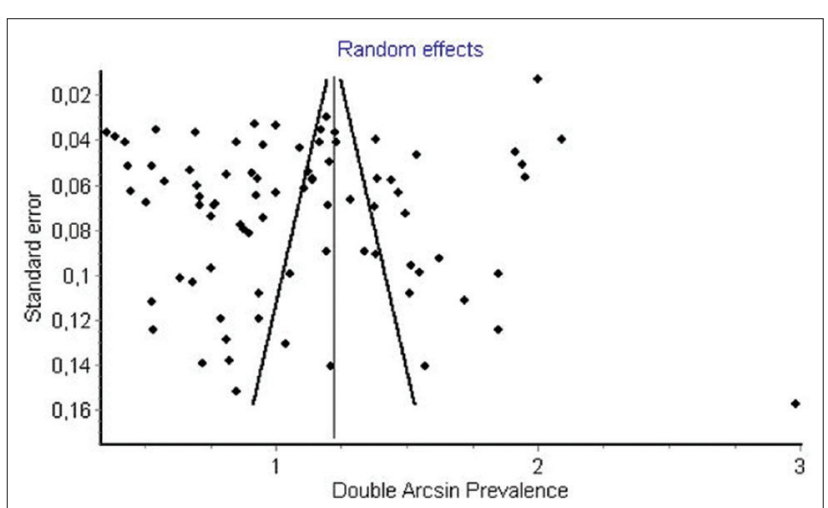

Figure-2: Funnel plot of double arcsinus seroprevalence estimates in food animals.

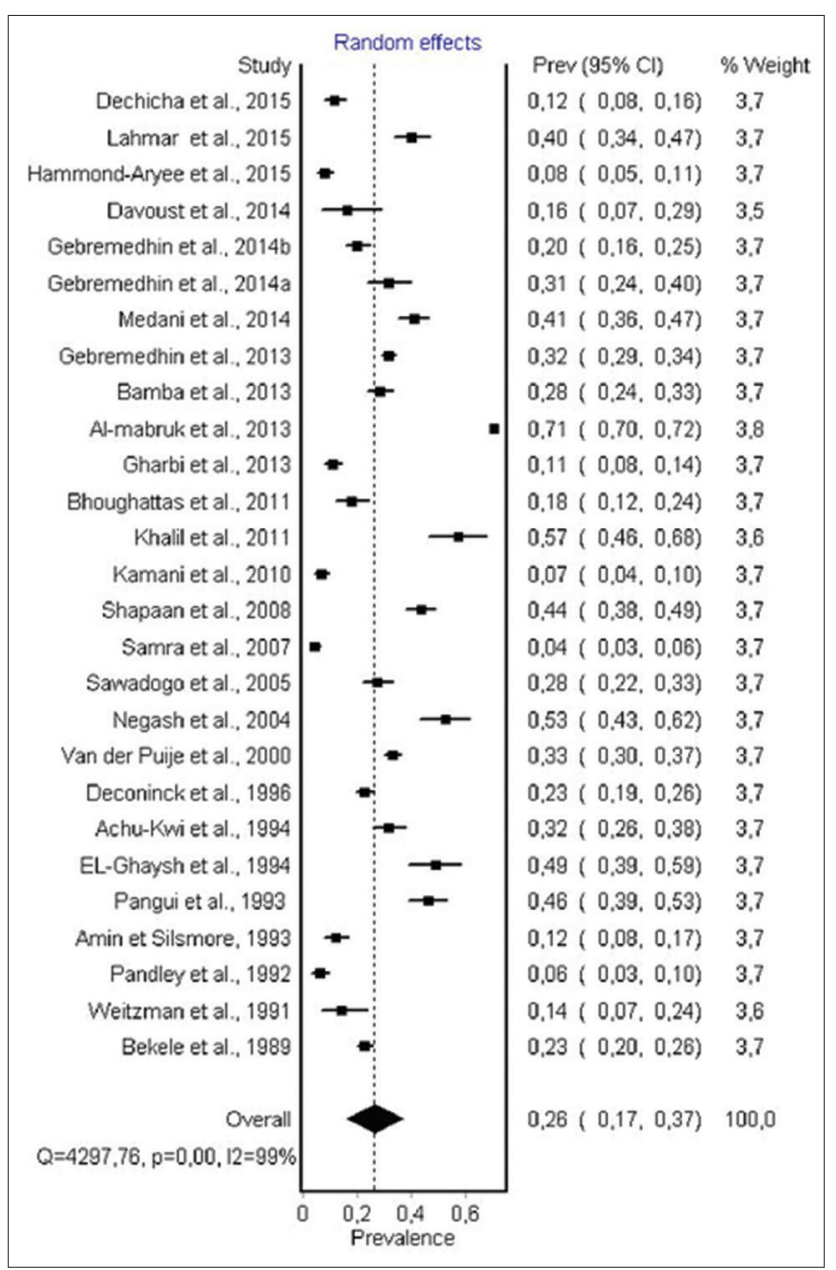

Figure-3: Forest plot of Toxoplasma gondii infection prevalence in sheep (random effect model). In a forest plot, each study is represented by a line, the width of the line represents the confidence intervals for effect estimate of each study, and area of the box indicates the weight given to each study. This description of forest plot is applied to all forest plots presented in Figures-3-8.

Among pigs, in addition to age (Table-1) [88]; management system (Table-1) $[40,80]$ and breed [88]; the main risk factor identified was feeding type containing bio products (Table-1) [42].

Otherwise, among chicken, the major risk factor for presence of anti-T. gondii were cats density (Table-1) [37] and management system (Table-1) [64].

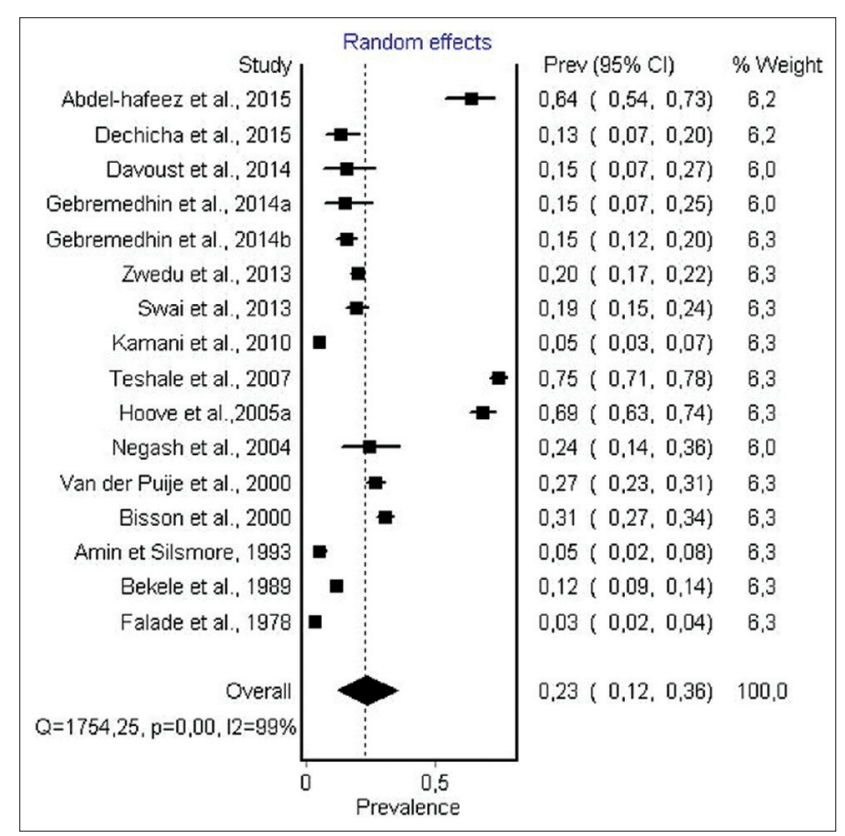

Figure-4: Forest plot of Toxoplasma gondii infection prevalence in goat (random-effects model).

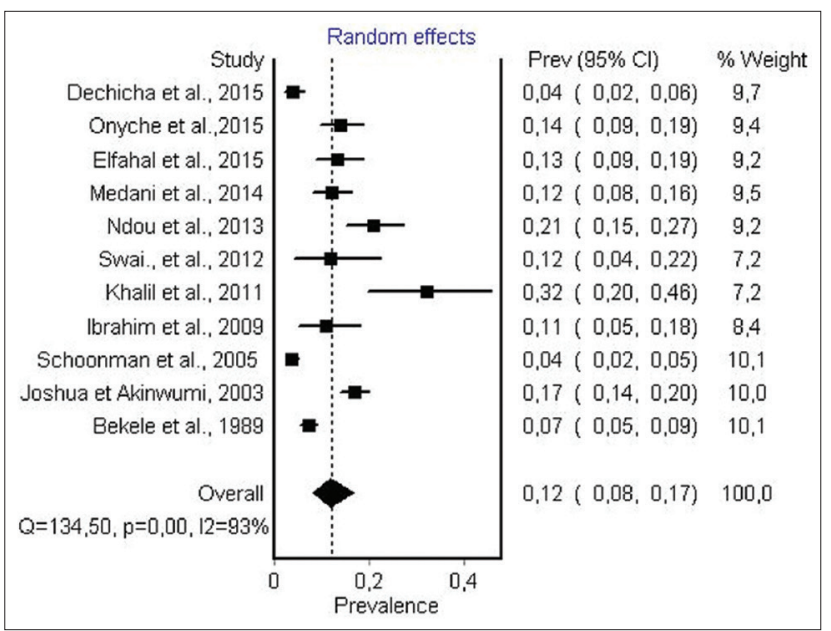

Figure-5: Forest plot of Toxoplasma gondii infection prevalence in cattle (random-effects model).

\section{Discussion}

Toxoplasmosis is one of the most widespread zoonoses in warm-blooded animals. The results of this review allowed us to compare estimates of infection with $T$. gondii and exposure to the parasite in different food animals from Africa. T. gondii infection is widespread in some food animals, especially chicken, camel, pig, sheep, and goats which represent the most consumed animal species in Africa for their meat, and there is a wide disparity between the levels of infection in different animal species considered.

The estimated prevalence of anti- $T$. gondii antibody in ruminants was significantly different: Camels, 36\% (95\% CI 18-56\%); sheep, 26.1\% (95\% CI $17.0-37.0)$ and goat, $22.9 \%$ (95\% CI $12.3-36.0 \%)$ were the most infected hosts, while the lowest seroprevalence were recorded in cattle $12 \%(95 \% \mathrm{CI}$ $8-17 \%)$. The highest infection levels are recorded in 


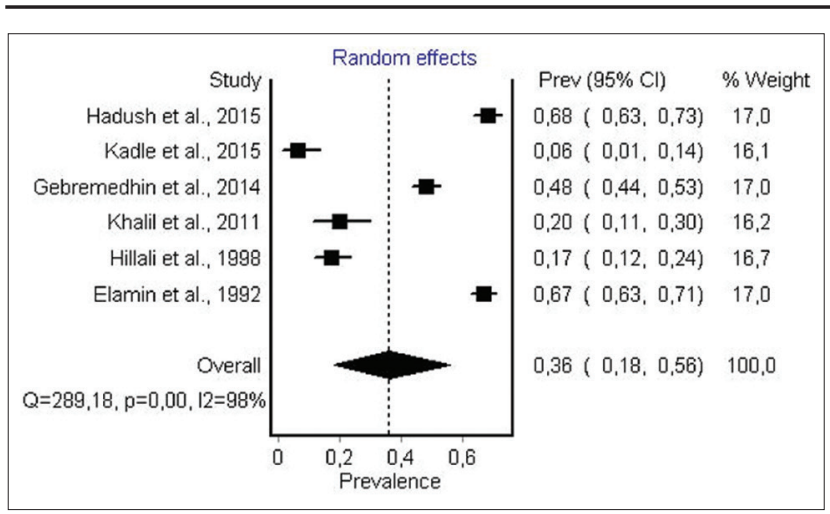

Figure-6: Forest plot of Toxoplasma gondii infection prevalence in camel (random-effects model).

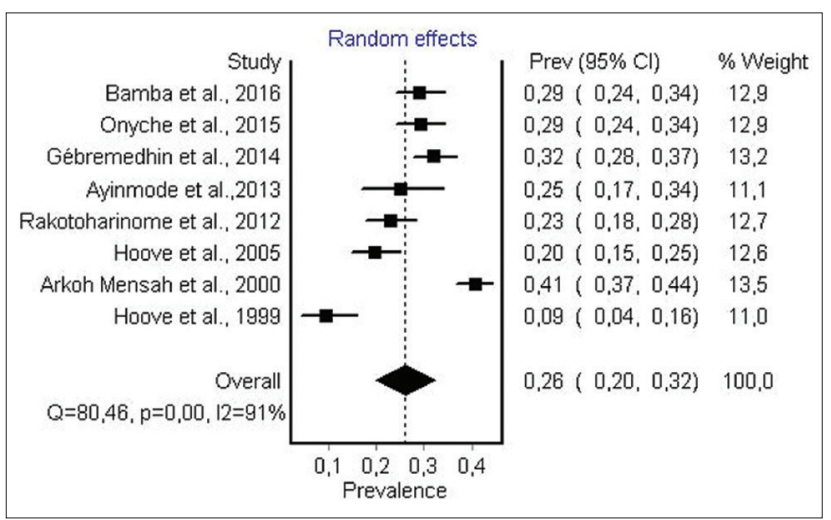

Figure-7: Forest plot of Toxoplasma gondii infection prevalence in pig (random-effects model).

\begin{tabular}{|c|c|c|c|}
\hline & Random effects & & \\
\hline Study & & $\operatorname{Prev}(95 \% \mathrm{Cl})$ & $\%$ Weight \\
\hline Gebremedhin et al., 2015b & 둘: & $0,30(0,27,0,34)$ & 6,6 \\
\hline Bhoughattas et al., 2014 & & $1,00(0,96,1,00)$ & 5,6 \\
\hline Ayinmode et al 2014 & & $0,36(0,30,0,42)$ & 6,5 \\
\hline Tilahun et al., 2013 & $\rightarrow-$ & $0,64(0,52,0,75)$ & 5,9 \\
\hline Barakat et al., 2012 & & $0,38(0,30,0,47)$ & 6,3 \\
\hline Aboelhadid et al., 2013 & $=$ & $0,14(0,10,0,19)$ & 6,5 \\
\hline Dubey et al., 2008 & & $0,47(0,37,0,58)$ & 6.1 \\
\hline Lindstrom et al., 2008 & - & $0,50(0,36,0,64)$ & 5,8 \\
\hline Dubey et al., 2005 & & $0,40(0,32,0,49)$ & 6,3 \\
\hline dubey et al, 2005 & & $0,06(0,02,0,13)$ & 6.1 \\
\hline Deyab et al., 2005 & 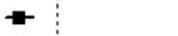 & $0,19(0,13,0,25)$ & 6.4 \\
\hline Dubey et al., 2003 & & $0,47(0,38,0,57)$ & 6,2 \\
\hline EL-Massry et al., 2000 & - & $0,19(0,13,0,25)$ & 6.4 \\
\hline Rifaat et al., 1969 & & $0,20(0,12,0,29)$ & 6.1 \\
\hline Hassanain.,1997 & & $0,33(0,30,0,37)$ & 6,6 \\
\hline Aganga et al., 1984 & 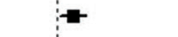 & $0,45(0,39,0,51)$ & 6,5 \\
\hline \multirow{3}{*}{$\begin{array}{r}\text { Overall } \\
Q=317,07, p=0,00,12=95 \%\end{array}$} & & $0,37(0,29,0,46)$ & 100,0 \\
\hline & & & \\
\hline & $\begin{array}{c}0,5 \\
\text { Prevalence }\end{array}$ & & \\
\hline
\end{tabular}

Figure-8: Forest plot of Toxoplasma gondii infection prevalence in chicken (random-effects model).

chickens $37.4 \%$ (95\% CI 29.2-46.0\%), while moderate pooled seroprevalence were obtained in pigs $26 \%$ (95\% CI 20.0-32.0). However, within each animal species a visible heterogeneity was observed, with a seroprevalence of antibodies ranging from $3.6 \%$ to $100 \%$ (Table-1) [46,79], as shown in the forest plots (Figures-3-8).
The overall pooled estimate in small ruminants was significant and the infection is more common in sheep which represents the most sensitive species to infection [8]. The highest prevalence were obtained in Ethiopia, 74.80\% (Table-1) [74] and Zimbabwe, $68.58 \%$ (Table-1) [78]. This result shows the variability of infection rates from one region to another within the same species. In most serological studies from sheep and goats included in the meta-analysis, age is considered an important risk factor, as higher seropositivity is found in older animals (Table-1) $[49,56,69,86]$. This result is in agreement with the results of studies conducted in France and Iran but in all the world [105-107]. According to many authors, the highest prevalence were reported in farms with epizootic abortions (Table-1) [58,108], while lower seroprevalence was recorded in intensively managed sheep systems (Table-1) $[56,78,109]$. Toxoplasmosis causes heavy economic losses to sheep industry worldwide and losses are mainly due to abortion and other reproductive failure [110-111]. The ingestion of undercooked meat from infected sheep, especially lamb is considered an important source of infection for humans [112]. Therefore, the estimate demonstrates the risk associated with the consumption of raw products derived from small ruminants in countries where the infection rate is high (Table-1) [50,68]. Usually, raw or undercooked lamb meat is considered a delicacy in some countries and is therefore considered an important source of infection. On the other hand, adult sheep meat is often well cooked, and therefore, probably poses a lower risk of infection to the consumer than lamb meat [112].

In pigs, $T$. gondii infection prevalence ranged from 26.80 to 40.60 excluding one study from Zimbabwe in 1999 reporting a prevalence of 09.60 (Table-1) [89], and lower prevalence rates were recorded in other regions around the world. Thus, prevalence of $28.9 \%$ was found in fattening pigs in Serbia [113], 20\% in Argentina [114], and 15.6\% in Portugal [115]. Poljak et al. [116] reported prevalence in pig farms from Canada of 11.6 in 2001, 0\% in 2003 and 1.2\% in 2004. High infection rate recorded in some African countries may be due to an extensive management system of pigs which is very widespread in Africa. Studies conducted in Ghana, Ethiopia and Zimbabwe have shown that a high prevalence of $T$. gondii was observed in extensively managed pig or backyard scavenging pigs than an intensively managed pig, hence the importance of modern intensive farming systems in reducing the prevalence of $T$. gondii infection in domestic pigs (Table-1) $[36,80]$. According to Gamble et al., the prevalence of $T$. gondii in pigs is also influenced by management systems [117]. In poorly managed non-confinement systems, seroprevalence in pigs was as high as 68\% [8]. Moreover, most studies conducted in Ghana, Zimbabwe and Ethiopia revealed that, the age of the animal, the Breed, and the management practices appeared to be the major determinants of prevalence of 
antibodies against $T$. gondii (Table-1) [40,80,88]. Most pigs acquire $T$. gondii infection postnatally by ingestion of oocysts from contaminated environment or ingestion of infected tissues of animals. Few pigs become infected prenatally by transplacental transmission of the parasite. Raising pigs indoors in confinement has greatly reduced $T$. gondii infection in pigs, but the recent trend of organic farming is likely to increase $T$. gondii infection in pigs [8]. The consumption of pork infected by $T$. gondii is one of the main risk factors for human infection [5,112]. Pork is known as one of the most important sources of $\mathrm{T}$. gondii infection in many countries such as China and USA, most human infections were associated with Pork consumption [3].

The highest estimated prevalence of anti T. gondii antibody was record in chickens $37.41 \%$ (95\% CI $29.20-46.00 \%$ ) with seroprevalence that ranged from $6.32 \%$ to $100 \%$ (Table- 1 ) [46,76]. Chickens are considered one of the most important hosts in the epidemiology of $T$. gondii infection because they are an efficient source of infection for cats that excrete the environmentally resistant oocysts and because humans may become infected with this parasite after eating undercooked infected chicken meat [118]. Studies from Tunisia, Ethiopia, and Uganda revealed very high prevalence of anti- $T$. gondii antibody among chicken, not encountered in any African country (Table-1) $[46,54,72]$, suggesting high environmental contamination by oocysts of $T$. gondii excreted by cats in these countries. the prevalence of $24.4 \%$ was reported in free-range (FR) chickens from Indonesia, $12.5 \%$ in chickens from Italy, $30 \%$ in chickens from Poland, and $24.2 \%$ in chickens from Vietnam by Dubey et al. (Table-1) [71]. In rural areas from Brazil, a prevalence higher than $50 \%$ in free ranging chickens was identified, indicating also a widespread contamination of rural environment of that country with T. gondii oocysts [119]. Furthermore, the prevalence rates were higher among FR than commercial farm chickens according to many authors (Table-1) [37,64]. Higher seroprevalence particularly in free range chickens (house-reared) refers to the public health importance of chickens as source of zoonotic toxoplasmosis to human (Table-1) $[47,64]$. In developing sub-Saharan countries, chickens are killed at home or in unsupervised slaughter facilities and the viscera are left for scavengers or are improperly disposed and $T$. gondii infection can be transmitted to human if care is not taken to wash hands thoroughly after cutting meat and during cooking of meat [120].

Results indicate that the estimated prevalence of toxoplasmosis in cattle from Africa is the lowest obtained $12 \%$ (95\% CI 8-17\%, $\mathrm{p}<0.001)$ among different food animals. The highest and the lowest prevalence were recorded in Sudan, 32\%, and Tanzania, 4\%, respectively (Table-1) $[67,78]$. This overall estimate is higher than the infection rate reported in North of Portugal that was estimated at $7.5 \%$ in cattle [121]. In West Indies, a prevalence of $8.4 \%$ was reported [122].
In Brazil, the reported sero-prevalence was $49.4 \%$ in cattle from a highly endemic area of human toxoplasmosis [123]. Whereas in Malaysia and Vietnam, lower seroprevalence of $7.9 \%$ and $10.5 \%$ were, respectively, reported in cattle $[124,125]$. High prevalence of toxoplasmosis of cattle in some areas may be due to the following factors: Humid and temperate climate; the absence of routine treatment against feline toxoplasmosis, considerable cat abundance and last but not least exposure to cats and their oocysts. Several epidemiological studies have mentioned that the consumption of raw or undercooked beef could be considered as a risk for T. gondii infection in humans [126]. But according to Kijlstra and Jongert [112] and Dubey and Jones [3] transmission from cattle is not important for human infection. Given the low level of infection in cattle from Africa, we can assume that the risk for T. gondii infection in humans from beefs is low as compared to other hosts of $T$. gondii. Among ruminants, camels are the most infected species by $T$. gondii, 36\% (95\% CI 18-56\%). T. gondii infection rate in Africa ranged from $17 \%$ to $68 \%$ and the highest rates were obtained in Sudan (Table-1) [97]. A higher prevalence has been reported from Turkey (90.9\%) [127], while lower seroprevalence was recorded earlier from Iran 3.12\% [128] and Saudi Arabia 6.5\% [129].

Overall, the variation of seroprevalence of T. gondii infection among different species might be due to the difference in density of cats and wild felids around farm, climatic conditions [130], farming and management practices [3], sample size, cutoff titer, duration of studies, and sensitivity difference in the serological tests employed. According to Guo et al. [131], the heterogeneity in prevalence could also be related to the presence of risk factors including farm type, feeding practices, presence of cats, rodent control and bird control methods, farm management, carcasses handling and disposal, and water source and quality. Moreover, studies carried out in distinct countries and various climatic conditions affect the results that could be another reason for this heterogeneity.

Results from some studies showed significant relation between animal age and $T$. gondii infection among all hosts. It shows a higher prevalence in adults animals than young which may be resulted from more exposure during animal growth. Animals acquire Toxoplasma infection merely via ingestion of oocyst and when prevalence is considerably high. There is a widespread oocyst contamination of the environment because of fecal contamination of soil and groundwater either by domestic or feral cats. Understanding prevalence rate of animal toxoplasmosis will help us to estimate the rate of human toxoplasmosis and it can be a good indicator of environment and final host contamination [107]. This point is extremely important to mention that it is not easy to consider prevention and control program without enough information about prevalence 
of toxoplasmosis in animal since they are a major source of transmission to human.

Given the vital role of animals in the transmission of $T$. gondii to humans via their products (meat and milk) and the prominent role of cats in disseminating and contamination of the environment by oocysts [1], more emphasis should be placed on the prevention of animal toxoplasmosis in Africa.

Caution is warranted in the interpretation of results of $T$. gondii prevalence in camel. Regarding such species, the prevalence data used in this study were analyzed based on a limited number of national studies, and nationwide surveys are not available in these meat animals, which resulted in a wide $95 \% \mathrm{CI}$ of the estimated prevalence.

\section{Conclusion}

This systematic review was performed to evaluate the prevalence of $T$. gondii infection among sheep, goat, cattle, pig, camel, and chicken which represent the most consumed food animal species in different African countries. The Random-effects meta-analysis approach in this current study provided an estimate of $T$. gondii prevalence in various meat animals with an increased level of precision. The widespread prevalence of $T$. gondii in sheep, chicken, camel, pig, and goats indicates a food safety concern in different African countries, especially countries where the infection is more important. Other studies are required for a better and continual evaluation of the occurrence of this zoonotic infection.

\section{Authors' Contributions}

The study was conceptualized and protocols were carried out by YA. ABNT and PS were involved in the database search, data extraction, statistical analysis, and manuscript written. CA and EY Studied titles and abstract of all the articles and retrieved data. Quality assessment of each study was completed independently by YGH and IY. MNA and SF oversaw data collection and analysis of statistical results. All authors have read and approved the content.

\section{Acknowledgments}

The authors are grateful to the Ministry of Higher Education and Scientific Research of Benin, Through the Doctoral Support Program No. 125 MESRS/CAB/ DC/SGM/DRFM/DRH/REGIE of 24 February 2015.

\section{Competing Interests}

The authors declare that they have no competing interests.

\section{References}

1. Ferguson, D.J. (2009) Toxoplasma gondii: 1908-2008, homage to Nicolle, Manceaux and Splendore. Mem. Inst. Oswaldo Cruz., 104(2): 133-148.

2. Dubey, J.P. (2010) Toxoplasmosis of Animals and Humans. $2^{\text {nd }}$ ed. CRC Press, Florida, USA.
3. Dubey, J.P. and Jones, J.L. (2008) Toxoplasma gondii infection in humans and animals in the United States. Int. J. Parasitol., 38(11): 1257-1278.

4. Moncada, P.A. and Montoya, J.G. (2012) Toxoplasmosis in the fetus and newborn: An update on prevalence, diagnosis and treatment. Expert. Rev. Anti Infect. Ther., 10(7): 815-828.

5. Tenter, A.M., Heckerotha, A.R. and Weiss, L.M. (2000) Toxoplasma gondii: From animals to humans. Int. J. Parasitol., 30: 1217-1258.

6. Patz, J.A., Graczyk, T.K., Geller, N. and Vittor, A.Y. (2000) Effects of environmental change on emerging parasitic diseases. Int. J. Parasitol., 30(12): 1395-1405.

7. Torgerson, P.R. and Mastroiacovo, P. (2013) The global burden of congenital toxoplasmosis: A systematic review. Bull. World Health Organ., 91(7): 501-508.

8. Dubey, J.P. (2009a) Toxoplasmosis in pigs: The last 20 years. Vet. Parasitol., 164: 89-103.

9. Dubey, J.P. (2009b) Toxoplasmosis in sheeps: The last 20 years. Vet. Parasitol., 152: 25-80.

10. Bourée, P., Dumazedier, D., Magdeleine, C. and Sobesky, G. (1997) Toxoplasmose cérébrale et SIDA à la martinique. Méd. Trop., 57(3): 259-261.

11. Weiss, L.M. and Dubey, J.P. (2009) Toxoplasmosis: A history of clinical observations. Int. J. Parasitol., 39(8): 895-901.

12. Torrey, E.F., Bartko, J.J., Lun, Z.R. and Yolken, R.H. (2007) Antibodies to Toxoplasma gondii in patients with schizophrenia: A meta-analysis. Schizophr. Bull., 33: 729-736.

13. Palmer, B.S. (2007) Meta-analysis of three case controlled studies and an ecological study into the link between cryptogenic epilepsy and chronic toxoplasmosis infection. Seizure, 16(8): 657-663.

14. Flegr, J., Klose, J., Novotná, M., Berenreitterová, M. and Havlíček, J. (2009) Increased incidence of traffic accidents in Toxoplasma-infected military drivers and protective effect $\mathrm{RhD}$ molecule revealed by a large-scale prospective cohort study. BMC Infect. Dis., 9: 72.

15. Leal, F.E., Cavazzana, C.L., deAndrade, H.F.J., Galisteo,A.Jr., de Mendonca, J.S. and Kallas, E.G. (2007) Toxoplasma gondii pneumonia in immunocompetent subjects: Case report and review. Clin. Infect. Dis., 44(6): e62-e66.

16. Pasquali, P. (2007) Infections au VIH et zoonoses. Food Agric. Organ., Vol.163.

17. Hammond-Aryee, K., Esser, M. and Van Helden, P.D. (2015) Toxoplasma gondii seroprevalence studies on humans and animals in Africa. S. Afr. Fam. Pract., 56(2): 119-124.

18. Available from: http://www.faostat.fao.org/site/569/default. aspx\#ancor. Accessed on 20-06-2016.

19. Cook, A.J.C., Gilbert, R.E., Buffolano, W., Zufferey, J., Petersen, E., Jenum, P.A., Foulon, W., Semprini, A.E. and Dunn, D.T. (2000) Sources of Toxoplasma infection in pregnant women: European multicentre case-control study. $B r$. Med. J., 321: 142-147.

20. Boyer, K.M., Holfels, E., Roizen, N., Swisher, C., Mack, D., Remington, J., Withers, S., Meier, P. and McLeod, R. (2005) Risk factors for Toxoplasma gondii infection in mothers of infants with congenital toxoplasmosis: Implications for prenatal management and screening. Am. J. Obstet. Gynecol., 192: 564-571.

21. FAO-OMS. (2015) Joint FAO/WHO food standards program codex committee on food hygiene. Forty-seventh session Boston, Massachusetts, United States of America, 9-13 November 2015.

22. Montoya, J.G. (2002) Laboratory diagnosis of Toxoplasma gondii infection and toxoplasmosis. J. Infect. Dis., 185(1): S73-S82.

23. Dubey, J.P., Thulliez, P., Weigel, R.M., Andrews, C.D., Lind, P. and Powell, E.C. (1995) Sensitivity and specificity of various serologic tests for detection of Toxoplasma gondii infection in naturally infected sows. Am. J. Vet. Res., 56(8): 1030-1036.

24. Villena, I., Durand, B., Aubert, D., Blaga, R., Geers, R., Thomas, M., Perret, C., Alliot, A., Escotte-Binet, S., 
Thebault, A., Boireau, P. and Halos, L. (2012) New strategy for the survey of Toxoplasma gondii in meat for human consumption. Vet. Parasitol., 183(3-4): 203-208.

25. Gamble, H.R., Dubey, J.P. and Lambillotte, D.N. (2005) Comparison of a commercial ELISA with the modified agglutination test for detection of Toxoplasma infection in the domestic pig. Vet. Parasitol., 128: 177-181.

26. Gonzales-Barron, U. and Butler, U. (2011) The use of meta-analytical tools in risk assessment for food safety. Food Microbiol., 28: 823-827.

27. Barron, U.G., Soumpasis, I., Butler, F., Prendergast, D., Duggan, S. and Duffy, G. (2009) Estimation of prevalence of Salmonella on pig carcasses and pork joints, using a quantitative risk assessment model aided by meta-analysis. J. Food Prot., 72: 274-285.

28. Gliner, G.A., Morgan, N.L. and Leech, O. (2009) Research Methods in Applied Settings: An Integrated Approach to Design and Analysis. $2^{\text {nd }}$ ed. Routledge, Abingdon, UK.

29. Hutton, B., Salanti, G., Caldwell, D.M., Chaimani, A., Schmid, C.H., Cameron, C., Ioannidis, J.P., Straus, S., Thorlund, K., Jansen, J.P., Mulrow, C., Catalá-López, F., Gøtzsche, P.C., Dickersin, K., Boutron, I., Altman, D.G. and Moher, D. (2015) The PRISMA extension statement for reporting of systematic reviews incorporating network meta-analyses of health care interventions: Checklist and explanations. Ann. Intern. Med., 162(11): 777-784.

30. Hoy, D., Brooks, P., Woolf, A., Blyth, F., March, L., Bain, C., Baker, P., Smith, E. and Buchbinder, R. (2012) Assessing risk of bias in prevalence studies: Modification of an existing tool and evidence of inter rater agreement. $J$. Clin. Epidemiol., 65: 934-939.

31. Available from: http://www.epigear.com/index_files/ metaxl.html. Accessed on 22 May 2016, 11h 55 min.

32. Doi, S.A., Barendregt, J.J. and Mozurkewich, E.L. (2011) Meta-analysis of heterogeneous clinical trials: An empirical example. Contemp. Clin. Trials, 32: 288-298.

33. Barendregt, J.J., Doi, S.A., Lee, Y.Y., Norman, R.E. and Vos, T. (2013) Meta-analysis of prevalence. J. Epidemiol. Community Health, 67: 974-978.

34. Sterne, J.A. and Egger, M. (2001) Funnel plots for detecting bias in meta-analysis: Guidelines on choice of axis. J. Clin. Epidemiol., 54: 1046-1055.

35. Higgins, J.P., Thompson, S.G., Deeks, J.J. and Altman, D.G. (2003) Measuring inconsistency in meta-analyses. Br. Med. J., 327: 557-560.

36. Bamba, S., Halos, F., Tarnagda, Z., Alanio, A., Macé, E., Moukoury, S., Sangaré, I., Guiguemdé, R., Costa, J.M. and Bretagne, S. (2016) Seroprevalence of Toxoplasma gondii and direct genotyping using mini-sequencing in free-range pigs in Burkina Faso. Int. J. Food Microbiol., 230: 10-15.

37. Gebremedhin, E.Z., Tesfamaryam, G., Yunus, H.A., Duguma, R., Tilahun, G., Di Marco, V. and Vitale, M. (2015b) Seroepidemiology of Toxoplasma gondii infection in free-range chickens (Gallus domesticus) of Central Ethiopia. Epidemiol. Infect., 143(3):608-617.

38. Abdel-Hafeez, E.H., Kamal, A.M., Abdelgelil, N.H. and Abdel-Fatah, M. (2015) Parasites transmitted to human by ingestion of different types of meat, El-Minia City, El-Minia Governorate, Egypt. J. Egypt. Soc. Parasitol., 45(3): 671-680.

39. Dechicha, A.S., Bachi, F., Gharbi, I., Gourbdji, E., Baazize-Ammi, D. and Guetarni, D. (2015) Seroepidemiological survey on toxoplasmosis in cattle, sheep and goats in Algeria. Afr. J. Agric. Res., 10(20): 2113-2119.

40. Onyiche, T.G.E. and Ademola, I.O. (2015) Seroprevalence of anti-Toxoplasma gondii antibodies in cattle and pigs in Ibadan, Nigeria. J. Parasit. Dis., 39(2): 309-314.

41. Elfahal, A.M., Elhassan, A.M., Hussien, M.O., Enan, K.A., Musa, A.B. and El Hussein, A.M. (2013) Seroprevalence of Toxoplasma gondii in dairy cattle with reproductive problems in Sudan. ISRN Vet. Sci., 89: 51-65.
42. Gebremedhin, E.Z., Kebeta, M.M., Asaye, M., Ashenafi, H., Di Marco, V. and Vitale, M. (2015a) First report on seroepidemiology of Toxoplasma gondii infection in pigs in central Ethiopia. BMC Vet. Res., 11: 59.

43. Hadush, A., Gebru, M.U., Zeru, F., Hadush, T., Tesfamaryam, G. and Feleke, A. (2015) Sero-epidemiology of camel toxoplasmosis and public awareness on its zoonotic importance in central afar region, North East Ethiopia. World Appl. Sci. J., 33(12): 1880-1887.

44. Lahmar, I., Lachkhem, A., Slama, D., Sakly, W., Haouas, N., Gorcii, M. and Babba, H. (2015) Prevalence of toxoplasmosis in sheep, goats and cattle in Southern Tunisia. $J$. Bacteriol. Parasitol., 6: 245.

45. Hammond-Aryee, K., Van Helden, L.S. and Van Helden, P.D. (2015) The prevalence of antibodies to Toxoplasma gondii in sheep in the Western Cape, South Africa. Onderstepoort J. Vet. Res., 82(1): E1-E5.

46. Boughattas, S., Ayari, K., Sa, T., Aoun, K. and Bouratbine, A. (2014) Survey of the parasite Toxoplasma gondii in human consumed ovine meat in Tunis city. PLoS One, 9(1): e85044.

47. Ayinmode, A.B. and Olaosebikan, R.I. (2014) Seroprevalence of Toxoplasma gondii infection in free ranged chicken from rural and urban settlements in Oyo State, Nigeria. Afr. J. Med. Med. Sci., 43 Suppl: 51-57.

48. Davoust, B., Mediannikov, O., Roqueplo, C., Perret, C., Demoncheaux, J.P., Sambou, M., Guillot, J. and Blaga, R. (2015) Serological survey of animal toxoplasmosis in Senegal. Bull. Soc. Pathol. Exot., 108(1): 73-77.

49. Gebremedhin, E.Z. and Gizaw, D. (2014a) Seroprevalence of Toxoplasma gondii Infection in sheep and goats in three districts of Southern nations, nationalities and peoples region of Ethiopia. World Appl. Sci. J., 31(11): 1891-1896.

50. Gebremedhin, E.Z., Abdurahaman, M., Hadush, T. and Tessema, T.S. (2014b) Seroprevalence and risk factors of Toxoplasma gondii infection in sheep and goats slaughtered for human consumption in Central Ethiopia. BMC Res. Notes, 7: 696.

51. Medani, M.Y.I. and Kamil, I.Y. (2014) Serosurvey of Toxoplasma gondii in sheep and cattle for human consumption in Khartoum slaughterhouses, Sudan. Int. J. Infect. Dis., 21: 157.

52. Kadle, A.A.H. (2014) Sero-prevalence of toxoposis in domestic animals in Benadir Region, Somalia. Open. J. Vet. Med., 4(08): 170.

53. Gebremedhin, E.Z., Yunus, H.A., Tesfamaryam, G., Tessema, T.S., Dawo, F., Terefe, G., Di Marco, V. and Vitale, M. (2014) First report of Toxoplasma gondii in camels (Camelus dromedarius) in Ethiopia: Bioassay and seroepidemiological investigation. BMC Vet. Res., 10: 222.

54. Tilahun, G., Tiao, N., Ferreira, L.R., Choudhary, S., Oliveira, S., Verma, S.K., Kwok, O.C., Molla, B., Saville, W.J., Medhin, G., Kassa, T., Aleme, H., Gebreyes, W.A., Su, C. and Dubey, J.P. (2013) Prevalence of Toxoplasma gondii from free-range chickens (Gallus domesticus) from Addis Ababa, Ethiopia. J. Parasitol., 99(4): 740-741.

55. Aboelhadid, S.M., Abdel-Ghany, A.E., Ibrahim, M.A. and Mahran, H.A. (2013) Seroprevalence of Toxoplasma gondii infection in chickens and humans in Beni Suef, Egypt. Glob. Vet., 11: 139-144.

56. Zewdu, E., Agonafir, A., Tessema, T.S., Tilahun, G., Medhin, G., Vitale, M., Di Marco, V., Cox, E., Vercruysse, J. and Dorny, P. (2013) Seroepidemiological study of caprine toxoplasmosis in East and West Shewa Zones, Oromia Regional State, Central Ethiopia. Res. Vet. Sci., 94(1): 43-48.

57. Swai, E.S. and Kaaya, J.E. (2013) A survey of Toxoplasma gondii antibodies by latex agglutination assay in dairy goats in Northern Tanzania. Trop. Anim. Health Prod., 45(1): 211-217.

58. Ndou, R.V., Pelele, W.P.S., Dzoma, B.M., Nyirenda, M., 
Motsei, L.E. and Bakunzi, F.R. (2013) An investigation into the prevalence of Toxoplasma gondii among indigenous, communally reared goats in the Mafikeng Area of the North West Province of South Africa. Life Sci. J., 8 Suppl 1:38-41.

59. Ayinmode, A.B. and Olaosebikan, R.I. (2014) Antibodies to Toxoplasma gondii in backyard and wandering pigs in Ibadan, Nigeria: Implications for pork consumption. Bull. Anim. Health Prod. Afr., 61(3): 493-497.

60. Gebremedhin, E.Z., Agonafir, A., Tessema, T.S., Tilahun, G., Medhin, G., Vitale, M., Di Marco, V., Cox, E., Vercruysse, J. and Dorny, P. (2013) Seroepidemiological study of ovine toxoplasmosis in East and West Shewa Zones of Oromia Regional State, Central Ethiopia. BMC Vet. Res., 9: 117 .

61. Bamba, S., Kamga-Waladjo, A.R., Cissé, M. and Tarnagda, Z. (2012, 2013) Serological survey on bovine toxoplasmosis in Bobo-Dioulasso, Burkina Faso. Rev. Med. Vet. Trop., 65: 63-66.

62. Al-Mabruk, A.A., Alkhunfas, S.R., El-Buni, A.A., Annajar, B.B. and Elsaid, M.M.A. (2013) Seroprevalence of Toxoplasma gondii antibodies in sheep from Libya. Int. J. Adv. Res., 1(9): 148-154.

63. Gharbi, M., Zribi, L., Jedidi, M., Chakkhari, H., Hamdi, S., R'hayem, S. and Darghouth, M.A. (2013) Prevalence of Toxoplasma gondii infection in sheep from Tunisia. Bull. Soc. Pathol. Exot., 106(3): 184-187.

64. Barakat, A.M., Salem, L.M., El-Newishy, A.M., Shaapan, R.M. and El-Mahllawy, E.K. (2012) Zoonotic chicken toxoplasmosis in some Egyptians Governorates. Pak. J. Biol. Sci., 15(17): 821-826.

65. Rakotoharinome, M., Andriamanivo, H., Blaga, R., Perret, C., Lacour, S., Grasset-Chevillot, A., Mace, P., Thomas, M., Villena, I., Aubert, D., Boireau, P. and Porphyre, V. (2012) Toxoplasmosis and trichinellosis: An epidemiological survey of pig population in Madagascar. European Multicolloquium on Parasitology (EMOP) XI, Cluj Napoca, Roumanie.

66. Swai, E.S. and Schoonman, L. (2012) A survey of zoonotic diseases in trade cattle slaughtered at Tanga city abattoir: A cause of public health concern. Asian. Pac. J. Trop. Biomed., 2(1): 55-60.

67. Khalil, K.M. and Abdel Gadir, A.E. (2007) Prevalence of Toxoplasma gondii antibodies in camels and their herders in three ecologically different areas in Sudan. J. Camel Pract. Res., 14(1): 11-13.

68. Boughattas, S. and Bouratbine, A. (2014) Prevalence of food-borne Toxoplasma gondii in free-ranging chickens sold in Tunis, Tunisia. J. Food Qual. Hazards Control, 1(3): 89-92.

69. Kamani, J., Mani, A.U. and Egwu, G.O. (2010) Seroprevalence of Toxoplasma gondii infection in domestic sheep and goats in Borno state, Nigeria. Trop. Anim. Health Prod., 42(4): 793-797.

70. Ibrahim, H.M., Huang, P., Salem, T.A., Talaat, R.M., Nasr, M.I., Xuan, X. and Nishikawa, Y. (2009) Short report: Prevalence of Neospora caninum and Toxoplasma gondii antibodies in northern Egypt. Am. J. Trop. Med. Hyg., 80(2): 263-267.

71. Dubey, J.P., Huong, L.T., Lawson, B.W., Subekti, D.T., Tassi, P., Cabaj, W., Sundar, N., Velmurugan, G.V., Kwok, O.C. and Su, C. (2008) Seroprevalence and isolation of Toxoplasma gondii from free-range chickens in Ghana, Indonesia, Italy, Poland, and Vietnam. J. Parasitol., 94(1): 68-71.

72. Lindstrom, I., Sundar, N., Lindh, J., Kironde, F., Kabasa, J.D., Kwok, O.C., Dubey, J.P. and Smith, J.E. (2008) Isolation and genotyping of Toxoplasma gondii from Ugandan chickens reveals frequentmultiple infections. Parasitology, 135: 39-45.

73. Shaapan, R.M., El-Nawawi, F.A. and Tawfik, M.A. (2008) Sensitivity and specificity of various serological tests for the detection of Toxoplasma gondii infection in naturally infected sheep. Vet. Parasitol., 153(3-4): 359-362.

74. Teshale, S. and Dumaitre, A. (2007) Serological survey of caprine toxopiasmosis in Ethiopia: Prevalence and risk factors. Parasite, 14(2): 155-159.

75. Samra, N.A., McCrindle, C.M., Penzhorn, B.L. and Cenci-Goga, B. (2007) Seroprevalence of toxoplasmosis in sheep in South Africa. J. S. Afr. Vet. Assoc., 78(3): 116-120.

76. Dubey, J.P., Graham, D.H., Dahl, E., Hilali, M., El-Ghaysh, A., Sreekumar, C., Kwok, O.C., Shen, S.K. and Lehmann, T. (2003) Isolation and molecular characterization of Toxoplasma gondii from chickens and ducks from Egypt. Vet. Parasitol., 114(2): 89-95.

77. Deyab, A.K. and Hassanein, R. (2005) Zoonotic toxoplasmosis in chicken. J. Egypt. Soc. Parasitol., 147(5): 341-350.

78. Hove, T., Lind, P. and Mukaratirwa, S. (2005b) Seroprevalence of Toxoplasma gondii infection in goats and sheep in Zimbabwe. Onderstepoort J. Vet. Res., 72(4): 267-272.

79. Schoonman, L.B., Wilsmore, T. and Swai, E.S. (2010) Seroepidemiological investigation of bovine toxoplasmosis in traditional and smallholder cattle production systems of Tanga Region, Tanzania. Trop. Anim. Health Prod., 42(4): 579-587.

80. Hove, T., Lind, P. and Mukaratirwa, S. (2005a) Seroprevalence of Toxoplasma gondii infection in domestic pigs reared under different management systems in Zimbabwe. Onderstepoort J. Vet. Res., 72(3): 231-237.

81. Sawadogo, P., Hafid, J., Bellete, B., Sung, R.T., Chakdi, M., Flori, P., Raberin, H., Hamouni, I.B., Chait, A. and Dalal, A. (2005) Seroprevalence of T. gondii in sheep from Marrakech, Morocco. Vet. Parasitol., 130(1-2): 89-92.

82. Negash, T. and Tilahun, G. (2004) Serological survey on toxoplasmosis in sheep and goats in Nazareth, Ethiopia. Re. Med. Vet., 155(10): 486-487.

83. Dubey, J.P., Karhemere, S., Dahl, E., Sreekumar, C., Diabate, A., Dabire, K.R., Vianna, M.C., Kwok, O.C. and Lehmann, T. (2005) First biologic and genetic characterization of Toxoplasma gondii isolates from chickens from Africa (Democratic Republic of Congo, Mali, Burkina Faso, and Kenya). J. Parasitol., 91(1): 69-72.

84. Joshua, R.A. and Akinwumi, K.A. (2004) Prevalence of antibodies to Toxoplasma gondii in four breeds of cattle at Ibadan, Nigeria. Trop. Vet., 21(3): 134-137.

85. El-Massry, A., Mahdy, O.A., El-Ghaysh, A. and Dubey, J.P. (2000) Prevalence of Toxoplasma gondii antibodies in sera of turkeys, chickens, and ducks from Egypt. J. Parasitol., 86(3): 627-628.

86. Van der Puije, W.N., Bosompem, K.M., Canacoo, E.A., Wastling, J.M. and Akanmori, B.D. (2000) The prevalence of anti-Toxoplasma gondii antibodies in Ghanaian sheep and goats. Acta Trop., 76(1): 21-26.

87. Bisson, A., Maley, S., Rubaire-Akiiki, C.M. and Wastling, J.M. (2000) The seroprevalence of antibodies to Toxoplasma gondii in domestic goats in Uganda. Acta Trop., 76(1): 33-38.

88. Arko-Mensah, J., Bosompem, K.M., Canacoo, E.A., Wastling, J.M. and Akanmori, B.D. (2000) The seroprevalence of toxoplasmosis in pigs in Ghana. Acta Trop., 76(1): 27-31.

89. Hove, T. and Dubey, J.P. (1999) Prevalence of Toxoplasma gondii antibodies in sera of domestic pigs and some wild game species from Zimbabwe. J. Parasitol., 85(2): 372-337.

90. Hilali, M., Romand, S., Thulliez, P., Kwok, O.C. and Dubey, J.P. (1998) Prevalence of Neospora caninum and Toxoplasma gondii antibodies in sera from camels from Egypt. Vet. Parasitol., 75(42-43): 269-271.

91. Hassanain, M.A. and Elfadaly, H.A. (1997) Biological assay of Toxoplasma gondii Egyptian mutton isolates. Int. J. Zool. Res., 7(4): 330-337.

92. Deconinck, P., Pangui, L.J., Akakpo, J., Garrouste, A., 
Ouattara, L., Roger, F., Tibayrenc, R. and Dorchies, P. (1996) Prevalence of toxoplasmosis in small ruminants in tropical Africa: Results of a sero-epidemiological survey of 1042 animals. Rev. Méd. Vét., 19: 30-36.

93. Achu-Kwi, M.D. and Ekue, N.F. (1994) Prevalence of Toxoplasma gondii antibodies in Djallonke sheep flocks in the Vina Division, Cameroon. Bull. Anim. Health Prod. Afr., 42(2): 89-92.

94. El-Ghaysh, A.A. and Mansour, M.M. (1994) Detection of antibodies to Toxoplasma gondii in an Egyptian sheepherd using modern serological techniques. J. Egypt. Assoc. Immunol., 1: 117-121.

95. Amin, J.D. and Silsmore, A.J. (1993) A serological survey of some abortifacient diseases of sheep and goats in the Maiduguri area of Nigeria. Bull. Anim. Health Prod. Afr., 41(2): 123-128.

96. Pangui, L.J., Lahamdi, A. and Samb, F. (1993) Use of IFI and ELISA in a serological survey of toxoplasmosis in sheep in Dakar-Senegal. Rev. Méd. Vét., 16: 25-29.

97. Elamin, E.A., Elias, S., Daugschies, A. and Rommel, M. (1992) Prevalence of Toxoplasma gondii antibodies in pastoral camels (Camelus dromedarius) in the Butana plains, mid-Eastern Sudan. Vet. Parasitol., 43(3-4): 171-175.

98. Pandey, V.S. and Van Knapen, F. (1992) The seroprevalence of toxoplasmosis in sheep, goats and pigs in Zimbabwe. Ann. Trop. Med. Parasitol., 86(3): 313-315.

99. Weitzman, G.L. and Stem, E.C. (1991) Preliminary serological survey for bluetongue and toxoplasmosis in sheep in Niger. Trop. Anim. Health Prod., 23(4): 258.

100. Bekele, T. and Kasali, O.B. (1989) Toxoplasmosis in sheep, goats and cattle in central Ethiopia. Vet. Res. Commun., 13(5): 371-375.

101. Aganga, A.O. and Belino, E.D. (1984) Toxoplasmosis in local breed of chicken in Zaria, Nigeria. Int. J. Zoonoses., 11(2): 170-172.

102. Falade, S. (1978) Toxoplasma gondii antibodies in Nigerian goats. Trop. Anim. Health Prod., 10(1): 175-177.

103. Rifaat, M.A., Morsy, T.A. and Sadek, M.S.M. (1969) Toxoplasmosis in chickens and pigeons in U.A.R. (Preliminary Report). J. Trop. Med. Hyg., 72: 193-194.

104. Arthur, M.J. and Blewett, D.A. (1988) IFAT detection of IgG specific to Toxoplasma in thoracic fluids from aborted lambs: Evaluation on routine diagnostic submissions. Vet. Rec., 122: 29-31.

105. Dumetre, A., Daniel, A., Luc, R., Aurelien, M. and Marie-Laure, D. (2006) Toxoplasma gondii infection in sheep from Haute-Vienne, France: Seroprevalence and isolate genotyping by microsatellite analysis. Vet. Parasitol., 142(3-4): 376-379.

106. Sharif, M., Sarvi, S., Shokri, A., Teshnizi, S.H., Rahimi, M.T., Mizani, A. and Daryani, A. (2015) Toxoplasma gondii infection among sheep and goats in Iran: A systematic review and meta-analysis. Parasitol. Res., 114(1): 1-16.

107. Guo, M., Dubey, J.P., Hill, D., Buchanan, R.L., Gamble, H.R., Jones, J.L. and Pradhan, A.K. (2015) Prevalence and risk factors for Toxoplasma gondii infection in meat animals and meat products destined for human consumption. J. Food Prot., 78: 457-476.

108. Dubey, J.P. and Kirkbride, C.A. (1989) Enzootic toxoplasmosis in sheep in North-Central United-States. J. Parasitol., 75: 673-676.

109. Ragozo, A.M.A., Yai, L.E.O., Oliveira, L.N., Dias, R.A., Dubey, J.P. and Gennari, S.M. (2008) Seroprevalence and isolation of Toxoplasma gondii from sheep from São Paulo state, Brazil. J. Parasitol., 94(6): 1259-1263.

110. Buxton, D., Maley, S.W., Wright, S.E., Rodger, S., Bartley, P. and Innes, E.A. (2007) Toxoplasma gondii and ovine toxoplasmosis: New aspects of an old story. Vet. Parasitol., 149(1): 25-28.

111. da Silva, A.F., Brandão, F.Z., Oliveira, F.C.R. and Ferreira, A.M.R. (2013) Toxoplasma gondii in the sheep industry: A global overview and the situation in Brazil. Rev. Bras. Ciên. Vet., 20(4): 179-188.

112. Kijlstra, A. and Jongert, E. (2008) Control of the risk of human toxoplasmosis transmitted by meat. Int. J. Parasitol., 38: 1359-1370.

113. Klun, I., Djurković-Djaković, O., Katić-Radivojević, S. and Nikolić, A. (2006) Cross-sectional survey on Toxoplasma gondii infection in cattle, sheep and pigs in Serbia: Seroprevalence and risk factors. Vet. Parasitol., 135(2): 121-131.

114. Venturini, M.C., Bacigalupe, D., Venturini, L., Rambeaud, M., Basso, W., Unzaga, J.M. and Perfumo, C.J. (2004) Seroprevalence of Toxoplasma gondii in sows from slaughterhouses and in pigs from an indoor and an outdoor farm in Argentina. Vet. Parasitol., 124(3): 161-165.

115. de Sousa, S., Ajzenberg, D., Canada, N., Freire, L., da Costa, J.C., Dardé, M.L. and Dubey, J.P. (2006) Biologic and molecular characterization of Toxoplasma gondii isolates from pigs from Portugal. Vet. Parasitol., 135(2): 133-136.

116. Poljak, Z., Dewey, C.E., Friendship, R.M., Martin, S.W., Christensen, J., Ojkic, D. and Chow, E. (2008) Pig and herd level prevalence of Toxoplasma gondii in Ontario finisher pigs in 2001, 2003, and 2004. Can. J. Vet. Res., 72(4):303-310.

117. Gamble, H.R., Brady, R.C. and Dubey, J.P. (1999) Prevalence of Toxoplasma gondii infection in domestic pigs in the New England states. Vet. Parasitol., 82(2): 129-136.

118. Jones, J.L. and Dubey, J.P. (2012) Foodborne toxoplasmosis. Clin. Infect. Dis., 55(6): 845-851.

119. de Oliveira, L.N., Costa Junior, L.M., de Melo, C.F., Ramos Silva, J.C., Bevilaqua, C.M., Azevedo, S.S. and Gennari, S.M. (2009) Toxoplasma gondii isolates from free-range chickens from the northeast region of Brazil. $J$. Parasitol., 95(1): 235-237.

120. Dubey, J.P. (2010) Toxoplasma gondii infections in chickens (Gallus domesticus): Prevalence, clinical disease, diagnosis and public health significance. Zoonoses Public Health, 57(1): 60-73.

121. Lopes, A.P., Dubey, J.P., Neto, F., Rodrigues, A., Martins, T., Rodrigues, M. and Cardoso, L. (2013) Seroprevalence of Toxoplasma gondii infection in cattle, sheep, goats and pigs from the North of Portugal for human consumption. Vet. Parasitol., 193(1): 266-269.

122. Chikweto, A., Kumthekar, S., Tiwari, K., Nyack, B., Deokar, M.S., Stratton, G. and Dubey, J.P. (2011) Seroprevalence of Toxoplasma gondii in pigs, sheep, goats, and cattle from Grenada and Carriacou, West Indies. $J$. Parasitol., 97(5): 950-951.

123. Costa, G.H.N., Cabral, D.D., Varandas, N.P., de Almeida Sobral, E., de Almeida Borges, F. and Castagnolli, K.C. (2001) Frequency of anti-Neospora caninum and anti-Toxoplasma gondii antibodies in bovine sera from the states of São Paulo and Minas Gerais. Sem. Ciên. Agrárias, 22(1): 61-66.

124. Chandrawathani, P., Nurulaini, R., Zanin, C., Premaalatha, B., Adnan, M., Jamnah, O. and Seah, T.C. (2008) Research note seroprevalence of Toxoplasma gondii antibodies in pigs, goats, cattle, dogs and cats in Peninsular Malaysia. Trop. Biomed., 25: 257-258.

125. Huong, L.T.T., Ljungström, B.L., Uggla, A. and Björkman, C. (1998) Prevalence of antibodies to Neospora caninum and Toxoplasma gondii in cattle and water buffaloes in Southern Vietnam. Vet. Parasitol., 75(1): 53-57.

126. Baril, L., Ancelle, T., Goulet, V., Thulliez, P., Tirard-Fleury, V. and Carme, B. (1999) Risk factors for Toxoplasma infection in pregnancy: A case-control study in France. Scand. J. Infect. Dis., 31(3): 305-309.

127. Utuk, A.E., Kirbas, A., Babur, C. and Balkaya, I. (2012) Detection of Toxoplasma gondii antibodies and some helminthic parasites in camels from Nevsehir Province of 
Turkey. Isr. J. Vet. Med., 67(2): 106-108.

128. Dehkordi, F.S., Borujeni, M.R.H., Rahimi, E. and Abdizadeh, R. (2013) Detection of Toxoplasma gondii in raw caprine, ovine, buffalo, bovine, and camel milk using cell cultivation, cat bioassay, capture ELISA, and PCR methods in Iran. Foodborne Pathog. Dis., 10(2): 120-125.

129. Al-Anazi, A.D. (2011) Prevalence of Neospora caninum and Toxoplasma gondii antibodies in sera from camels
(Camelus dromedarius) in Riyadh Province, Saudi Arabia. J. Egypt. Soc. Parasitol., 41: 245-250.

130. Montoya, J.G. and Liesenfeld, O. (2004) Toxoplasmosis. Lancet, 363: 1965-1976.

131. Guo, M., Mishra, A., Buchanan, R.L., Dubey, J.P., Hill, D.E. and Gamble, H.R. (2016) A systematic meta-analysis of Toxoplasma gondii prevalence in food animals in the United States. Foodborne Pathog. Dis., 13(3): 109-118.

$* * * * * * * *$

\section{Appendix}

Supplementary Table-S1: Quality score assessment based on the "risk of bias tool" (Hoy et al., 2012).

\begin{tabular}{|c|c|c|c|c|c|c|c|c|c|c|c|c|}
\hline Species & Study & Q1 & Q2 & Q3 & Q4 & Q5 & Q6 & Q7 & Q8 & Q9 & Q10 & Summary \\
\hline Pig & Bamba et al. [36] & 0 & 1 & 1 & 1 & 1 & 1 & 1 & 1 & 1 & 1 & 9 \\
\hline Chicken & Gebremedhin et al. [37] & 0 & 1 & 1 & 1 & 1 & 1 & 1 & 1 & 1 & 1 & 9 \\
\hline Goat & Abdel-Hafeez et al. [38] & 0 & 0 & 1 & 1 & 1 & 1 & 0 & 1 & 1 & 1 & 7 \\
\hline Sheep & Dechicha et al. [39] & 0 & 0 & 0 & 1 & 1 & 1 & 0 & 1 & 1 & 1 & 6 \\
\hline Goat & Dechicha et al. [39] & 0 & 0 & 0 & 1 & 1 & 1 & 0 & 1 & 1 & 1 & 6 \\
\hline Cattle & Dechicha et al. [39] & 0 & 0 & 0 & 1 & 1 & 1 & 0 & 1 & 1 & 1 & 6 \\
\hline Cattle & Onyiche and Ademola [40] & 0 & 0 & 1 & 1 & 1 & 1 & 1 & 1 & 1 & 1 & 8 \\
\hline Pig & Onyiche and Ademola [40] & 0 & 0 & 1 & 1 & 1 & 1 & 1 & 1 & 1 & 1 & 8 \\
\hline Cattle & Elfahal et al. [41] & 0 & 0 & 0 & 0 & 1 & 1 & 1 & 1 & 1 & 1 & 6 \\
\hline Pig & Gebremedhin et al.[42] & 0 & 0 & 1 & 1 & 1 & 1 & 1 & 1 & 1 & 1 & 8 \\
\hline Camel & Hadush et al. [43] & 0 & 1 & 1 & 1 & 1 & 1 & 1 & 1 & 1 & 1 & 9 \\
\hline Sheep & Lahmar et al. [44] & 0 & 0 & 0 & 1 & 1 & 1 & 1 & 1 & 1 & 1 & 7 \\
\hline Sheep & Hammond-Aryee et al. [45] & 0 & 1 & 1 & 1 & 1 & 1 & 1 & 1 & 1 & 1 & 9 \\
\hline Chicken & Boughattas et al. [46] & 0 & 0 & 1 & 1 & 1 & 1 & 1 & 1 & 1 & 1 & 8 \\
\hline Chicken & Ayinmode and Olaosebikan [47] & 0 & 1 & 1 & 1 & 1 & 1 & 1 & 1 & 1 & 1 & 9 \\
\hline Goat & Davoust et al. [48] & 0 & 0 & 1 & 1 & 1 & 1 & 1 & 1 & 1 & 1 & 8 \\
\hline Sheep & Davoust et al. [48] & 0 & 0 & 1 & 1 & 1 & 1 & 1 & 1 & 1 & 1 & 8 \\
\hline Sheep & Gebremedhin and Gizaw [49] & 0 & 1 & 1 & 1 & 1 & 1 & 1 & 1 & 1 & 1 & 9 \\
\hline Goat & Gebremedhin and Gizaw [49] & 0 & 1 & 1 & 1 & 1 & 1 & 1 & 1 & 1 & 1 & 9 \\
\hline Sheep & Gebremedhin et al. [50] & 0 & 1 & 1 & 1 & 1 & 1 & 1 & 1 & 1 & 1 & 9 \\
\hline Goat & Gebremedhin et al. [50] & 0 & 1 & 1 & 1 & 1 & 1 & 1 & 1 & 1 & 1 & 9 \\
\hline Cattle & Medani and Kamil [51] & 0 & 0 & 0 & 1 & 1 & 1 & 1 & 1 & 1 & 1 & 7 \\
\hline Sheep & Medani and Kamil [51] & 0 & 0 & 0 & 1 & 1 & 1 & 1 & 1 & 1 & 1 & 7 \\
\hline Camel & Kadle [52] & 0 & & 1 & 1 & 1 & 1 & 0 & 1 & 1 & 1 & 7 \\
\hline Camel & Gebremedhin et al. [53] & 0 & 1 & 1 & 1 & 1 & 1 & 1 & 1 & 1 & 1 & 9 \\
\hline Chicken & Tilahun et al. [54] & 0 & 1 & 1 & 1 & 1 & 1 & 1 & 1 & 1 & 1 & 9 \\
\hline Chicken & Aboelhadid et al. [55] & 0 & 0 & 1 & 1 & 1 & 1 & 1 & 1 & 1 & 1 & 8 \\
\hline Goat & Zwedu et al. [56] & 0 & 1 & 1 & 1 & 1 & 1 & 1 & 1 & 1 & 1 & 9 \\
\hline Goat & Swai and Kaaya [57] & 0 & 1 & 1 & 1 & 1 & 1 & 0 & 1 & 1 & 1 & 8 \\
\hline Cattle & Ndou et al. [58] & 0 & 1 & 1 & 1 & 1 & 1 & 1 & 0 & 1 & 1 & 8 \\
\hline Pig & Ayinmode and Olaosebikan [59] & 0 & 1 & 1 & 1 & 1 & 1 & 1 & 1 & 1 & 1 & 9 \\
\hline Sheep & Gebremedhin et al. [60] & 0 & 1 & 1 & 1 & 1 & 1 & 1 & 1 & 1 & 1 & 9 \\
\hline Sheep & Bamba et al. [61] & 0 & 0 & 1 & 1 & 1 & 1 & 1 & 1 & 1 & 1 & 8 \\
\hline Sheep & Al-mabruk et al. [62] & 1 & 1 & 1 & 1 & 1 & 1 & 0 & 1 & 1 & 1 & 9 \\
\hline Sheep & Gharbi et al. [63] & 0 & 0 & 1 & 1 & 1 & 1 & 1 & 1 & 1 & 1 & 8 \\
\hline Chicken & Barakat et al. [64] & 0 & 0 & 1 & 1 & 1 & 1 & 1 & 1 & 1 & 1 & 8 \\
\hline Pig & Rakotoharinome et al. [65] & 0 & 0 & 1 & 1 & 1 & 1 & 1 & 1 & 1 & 1 & 8 \\
\hline Cattle & Swai and Schoonman [66] & 0 & 0 & 0 & 1 & 1 & 1 & 0 & 1 & 1 & 1 & 6 \\
\hline Camel & Khalil and Abdel Gadir [67] & 0 & 1 & 1 & 1 & 1 & 1 & 0 & 1 & 1 & 1 & 8 \\
\hline Sheep & Khalil and Abdel Gadir [67] & 0 & 1 & 1 & 1 & 1 & 1 & 0 & 1 & 1 & 1 & 8 \\
\hline Sheep & Boughattas and Bouratbine [68] & 0 & 1 & 1 & 1 & 1 & 1 & 1 & 1 & 1 & 1 & 9 \\
\hline Sheep & Kamani et al. [69] & 0 & 0 & 1 & 1 & 1 & 1 & 1 & 1 & 1 & 1 & 8 \\
\hline Goat & Kamani et al. [69] & 0 & 0 & 1 & 1 & 1 & 1 & 1 & 1 & 1 & 1 & 8 \\
\hline Cattle & Ibrahim et al. [70] & 0 & 0 & 0 & 1 & 0 & 1 & 0 & 1 & 1 & 1 & 5 \\
\hline
\end{tabular}

$($ Contd...) 
Supplementary Table-S1: (Continued)

\begin{tabular}{|c|c|c|c|c|c|c|c|c|c|c|c|c|}
\hline Species & Study & Q1 & Q2 & Q3 & Q4 & Q5 & Q6 & Q7 & Q8 & Q9 & Q10 & Summary \\
\hline Chicken & Dubey et al., [71] & 0 & 0 & 0 & 1 & 1 & 1 & 1 & 1 & 1 & 1 & 7 \\
\hline Chicken & Lindstrom et al. [72] & 0 & 0 & 1 & 1 & 1 & 1 & 1 & 1 & 1 & 1 & 8 \\
\hline Sheep & Shapaan et al. [73] & 0 & 0 & 0 & 1 & 1 & 1 & 1 & 1 & 1 & 1 & 7 \\
\hline Goat & Teshale and Dumaitre [74] & 0 & 1 & 1 & 1 & 1 & 1 & 1 & 1 & 1 & 1 & 9 \\
\hline Sheep & Samra et al. [75] & 0 & 1 & 1 & 1 & 1 & 1 & 1 & 1 & 1 & 1 & 9 \\
\hline Chicken & Dubey et al. [76] & 0 & 0 & 1 & 1 & 1 & 1 & 1 & 1 & 1 & 1 & 8 \\
\hline Chicken & Deyab and Hassanein [77] & 0 & 1 & 1 & 1 & 1 & 1 & 1 & 1 & 1 & 1 & 9 \\
\hline Goat & Hove et al. [78] & 1 & 1 & 1 & 1 & 1 & 1 & 0 & 1 & 1 & 1 & 9 \\
\hline Cattle & Schoonman et al. [79] & 0 & 1 & 1 & 1 & 1 & 1 & 0 & 1 & 1 & 1 & 8 \\
\hline Pig & Hove et al. [80] & 0 & 1 & 1 & 1 & 1 & 1 & 0 & 1 & 1 & 1 & 8 \\
\hline Sheep & Sawadogo et al. [81] & 0 & 1 & 1 & 1 & 1 & 1 & 1 & 1 & 1 & 1 & 9 \\
\hline Sheep & Negash and Tilahun [82] & 0 & 1 & 1 & 1 & 1 & 1 & 1 & 1 & 1 & 1 & 9 \\
\hline Goat & Negash and Tilahun [82] & 0 & 1 & 1 & 1 & 1 & 1 & 1 & 1 & 1 & 1 & 9 \\
\hline Chicken & Dubey et al. [83] & 0 & 0 & 0 & 1 & 1 & 1 & 1 & 1 & 1 & 1 & 7 \\
\hline Cattle & Joshua and Akinwumi [84] & 0 & 1 & 1 & 1 & 1 & 1 & 0 & 1 & 1 & 1 & 8 \\
\hline Chicken & El-Massry et al. [85] & 0 & 0 & 1 & 1 & 1 & 1 & 1 & 1 & 1 & 1 & 8 \\
\hline Sheep & Van der Puije et al. [86] & 1 & 1 & 1 & 1 & 1 & 1 & 1 & 1 & 1 & 1 & 10 \\
\hline Goat & Van der Puije et al. [86] & 1 & 1 & 1 & 1 & 1 & 1 & 1 & 1 & 1 & 1 & 10 \\
\hline Goat & Bisson et al. [87] & 1 & 1 & 1 & 1 & 1 & 1 & 1 & 1 & 1 & 1 & 10 \\
\hline Pig & Arkoh Mensah et al. [88] & 1 & 1 & 1 & 1 & 1 & 1 & 1 & 1 & 1 & 1 & 10 \\
\hline Pig & Hove and Dubey [89] & 0 & 0 & 0 & 1 & 1 & 1 & 1 & 1 & 1 & 1 & 7 \\
\hline Camel & Hilali et al. [90] & 0 & 1 & 1 & 1 & 1 & 1 & 1 & 1 & 1 & 1 & 9 \\
\hline Chicken & Hassanain and Elfadaly [91] & 0 & 0 & 1 & 1 & 1 & 1 & 0 & 1 & 1 & 1 & 7 \\
\hline Sheep & Deconinck et al. [92] & 0 & 0 & 0 & 1 & 1 & 1 & 0 & 1 & 1 & 1 & 6 \\
\hline Sheep & Achu-Kwi and Ekue [93] & 0 & 0 & 1 & 1 & 1 & 1 & 0 & 1 & 1 & 1 & 7 \\
\hline Sheep & El-Ghaysh and Mansour [94] & 0 & 0 & 1 & 1 & 1 & 1 & 1 & 1 & 1 & 1 & 8 \\
\hline Goat & Amin and Silsmore [95] & 0 & 1 & 1 & 1 & 1 & 1 & 0 & 1 & 1 & 1 & 8 \\
\hline Sheep & Pangui et al. [96] & 0 & 0 & 1 & 1 & 1 & 1 & 0 & 1 & 1 & 1 & 7 \\
\hline Camel & Elamin et al. [97] & 0 & 1 & 1 & 1 & 1 & 1 & 0 & 1 & 1 & 1 & 8 \\
\hline Sheep & Pandley and Mansour [98] & 1 & 1 & 1 & 1 & 1 & 1 & 1 & 1 & 1 & 1 & 10 \\
\hline Sheep & Weitzman et al. [99] & 0 & 1 & 1 & 1 & 1 & 1 & 0 & 1 & 1 & 1 & 8 \\
\hline Sheep & Bekele and Kasali [100] & 0 & 1 & 1 & 1 & 1 & 1 & 0 & 1 & 1 & 1 & 8 \\
\hline Goat & Bekele and Kasali [100] & 0 & 1 & 1 & 1 & 1 & 1 & 0 & 1 & 1 & 1 & 8 \\
\hline Cattle & Bekele and Kasali [100] & 0 & 1 & 1 & 1 & 1 & 1 & 0 & 1 & 1 & 1 & 8 \\
\hline Chicken & Aganga and Belino [101] & 0 & 0 & 1 & 1 & 1 & 1 & 0 & 1 & 1 & 1 & 7 \\
\hline Goat & Falade [102] & 0 & 0 & 1 & 1 & 1 & 1 & 0 & 1 & 1 & 1 & 7 \\
\hline Chicken & Rifaat et al. [103] & 0 & 0 & 1 & 1 & 1 & 1 & 0 & 1 & 1 & 1 & 7 \\
\hline
\end{tabular}

